
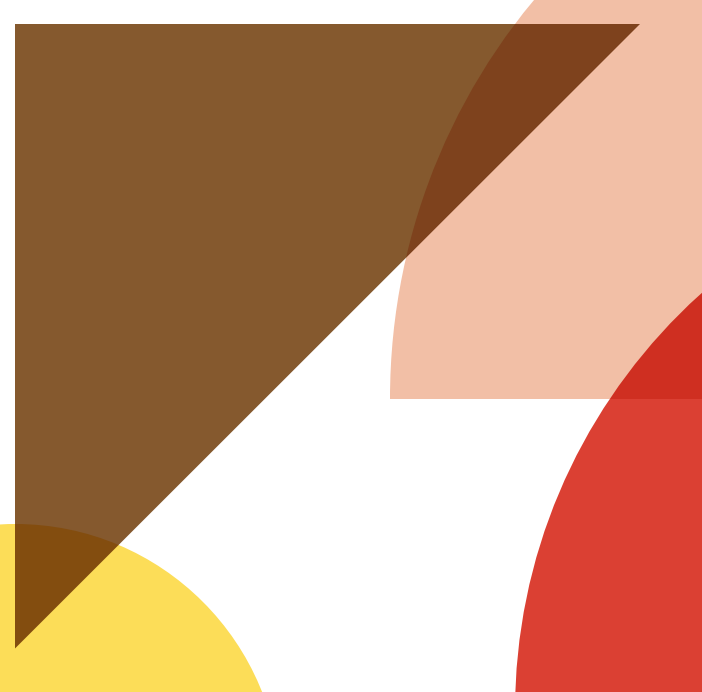

Skills for a Changing World:

\title{
National Perspectives and
}

\section{the Global Movement}

Esther Care, Helyn Kim, Kate Anderson, and Emily Gustafsson-Wright 
Esther Care is a senior fellow at the Center for Universal Education at Brookings Helyn Kim is a senior research associate at the Center for Universal Education at Brookings Kate Anderson is a project director and associate fellow at the Center for Universal

Emily Gustafsson-Wright is a fellow at the Center for Universal Education at Brookings

Skills for a Changing World is a project of the Center for Universal Education at Brookings and the LEGO Foundation that seeks to ensure all children have high-quality learning

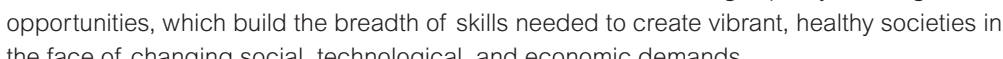
Acknowledgments

Our thanks go to Quest Research Services and Ipsos, who made this study possible in Kenya South Africa, Mexico, and the Philippines Special thanks to the stakeholders who participated in the study and discussed their attitudes and perspectives on the development of breadth of skills in school-age children, as well as the education system

more broadly.

We would like to extend our sincere appreciation to the peer reviewers, namely Christina Kwauk of the Brookings Instrtution and Claire Scoular of the University of Izzy Boggild-Jones for their research assistance, as well as Renée McAlpin. Eileen McGivney, Joshua Miller, Charlie Piggott, and Lindsay Reed for reviewing drafts and providing feedback.

Support for this publication and research effort was generously provided by the LEGO Foundation.

Brookings recognizes that the value it provides is in its absolute commitment to quality independence, and impact. Activities supported by itis donors reffect this commitment, a (n)

The Brookings Institution is a nonprofit organization devoted to independent research and policy solutions. Its mission is to conduct high-quality, independent research and, based on that research, to provide innovative, practical recommendations for policymakers and those of its author(s) and do not reflect the views of the Institution its management or its other scholars
TABLE OF CONTENTS

\section{Executive summary}

Introduction

Mexico

South Africa

Kenya

The Philippines

Themes across the four countries

Endnotes

References

Tables

Table 1. Associations between identification of skills across categories

Table 2. The number of focus group discussions and individual interviews conducted in each country

Table 3. Stakeholders' identification of most important skills for children and factors associated

$$
\text { with a successful person }
$$

Table 4. Challenges and concerns of the education system in Mexico by stakeholder group

Table 5. Skills across iterations of South Africa curricula

Table 6. Challenges and concerns of the education system in South Africa by stakeholder group

Table 7. Challenges and concerns of the education system in Kenya by stakeholder group

Table 8. Challenges and concerns of the education system in The Philippines by stakeholder group

Figures

Figure 1. The global movement

Figure 2. The learning environments

Figure 3. Level of contact to the student by stakeholder group 


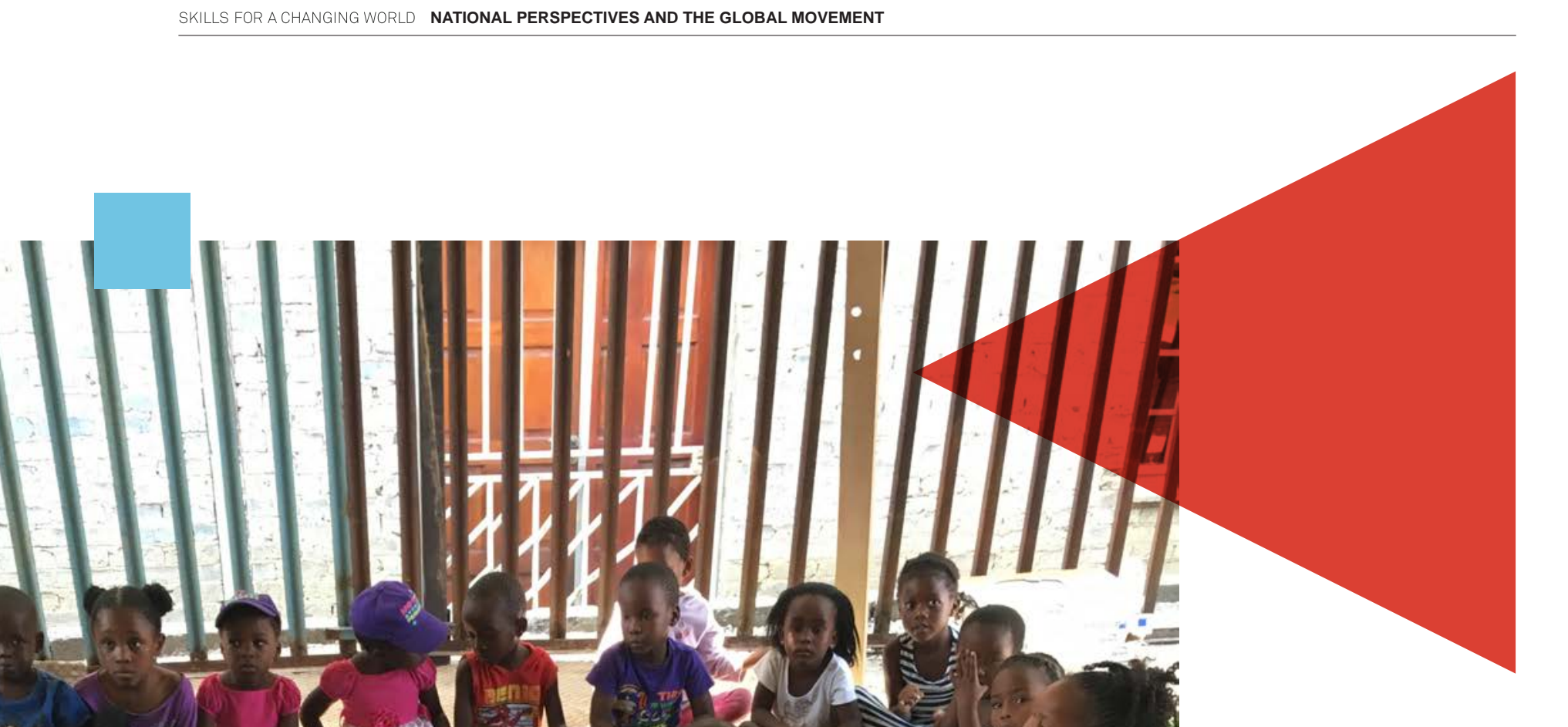

\section{Executive summary}

The Skills for a Changing World project presents evidence of a movement of education systems globally toward a more explicit focus on a broad range of skills that our 21st century society needs and demands. This movement can be seen in the vision and mission statemovement can be seen in the vision and mission state
ments of education systems as well as through their ments of education systems as well as through their
curricula. Although clearly endorsed at the policy leve implementation is just beginning in some countries. The issues surrounding this, particularly in the contex of within-country social and economic changes, are brought to light in this report by a study of education stakeholders in four countries-Mexico, South Africa, Kenya, and the Philippines.

Public education systems across 113 countries have defined education as being much more than equipping students with basic academic skills or technical skills for the world of work. A large number of countries identify specific skills such as problem solving and communication as valuable, and a smaller number of countres provide additonal detals about how these skills are integrated into he curiculum and how hey skills are integrated into the curniculum and how they are expected to develop through the years of forma education.

The broader society in which each student exists influences his or her understanding of what is import- ant and what is valued. We sought to understand the attitudes and perceptions of key education stakeholdrs by reviewing the education space in Mexico, South Africa, Kenya, and the Philippines, which have all recently extended mandated years of education and/or included a focus on 21st century skills in their offerings to students. Through interviews and focus groups, parents, community members, teachers, teacher trainers, and education administration and policy personne answered two primary questions concerning skills most highly valued in their communities: (1) What are the skills you associate with a successful person?; and and students to develop?

For both questions, responses from the stakeholders were organized into four categories-21st century skills, academic skills, character traits, and workforce and society characteristics.

Overall, when describing factors of success and identifying highly valued skills, three broad patterns are noticeable: (1) There are differences between the stakeholder groups that work closely with the child (i.e., parents, teachers) and the groups that are more distant from the child (i.e., teacher trainers, non-government, and government actors); (2) certain skills 
and traits are mentioned by all countries; and, (3) there are clear differences between countries in the factors and skills that are highly valued and emphasized.

In terms of characterizing the factors for success, the skills most frequently mentioned were communication social and interpersonal skills as a generic skillset, and critical and analytical thinking. However, 21st century skills, for the most part, were not associated with how parents defined success. Parents, instead, endorsed characteristics such as confidence, independence and responsibility, being productive members of society, happiness, and possessing appropriate morals and values as the most important. In contrast, 21 st century skills are featured as contributors to success for the more distant stakeholder groups. Across all four countries, non-government and government personnel emphasized communication, social skills, critical thinking, and technology and computer skills.

The skills that are highly valued for learners, however, include a broad range of 21 st century skills, such as collaboration, communication, creativity, critical thinking, social and interpersonal skills, technology and computer skills, and listening skills-these all being mentioned most frequently by parents and teachers. School administrators and teacher trainers placed greater emphasis on critical and analytical thinking. self-regulation, and academic skills. Government personnel tended to evenly nominate 21 st century and academic skills, character traits, and workforce and society characteristics. At the broadest level, therefore, data indicated that workforce and society characteristics seem to be associated mainly with success, whereas 21 st century skills and academic skills are highly valued for the learner.

Overall, evidence from the four countries points to the fact that socio-economic realities and politics clearly influence the views of the stakeholders about what education is offering and how it is changing. The views help to define some of the challenges faced, includ- ing the big one- how to teach and assess these new areas of focus in the education system. Understanding that children need a particular set of skills to live constructively in the 21st century is not the same as an in depth understanding of what those skills are, how they develop, or how to teach them.

\section{KEY FINDINGS}

Stakeholders across all four countries highly value 21 st century skills for learners. This pattern is different from factors of success, where character raits and workforce and society characteristics are emphasized.

2. Within each country, there appears to be tension between recognizing the importance of holisticaly-developed learners and the current structures of the education system that limits what is feasible to accomplish in classrooms.

3. Attitudes and perceptions of key stakeholders reflect the priorities of each country. Countries may face similar challenges and emphasize the same kinds of skills, but the current context and priorities of each individual country drive the unique perspectives and the conversations surrounding educational issues.

4. Stakeholder groups who work closely with the learner (i.e., parents and teachers), as well as government personnel, emphasize the importance of skills for success. However, the stakeholder groups in between (i.e., teacher trainers, representatives from nongovernmental organizations) were sparse in identifying the factors and skills related to success, despite the fact that these groups have a say in how to implement in classrooms and train teachers.

\section{Introduction}

In the Skills for a Changing World project, we are exploring the new demands placed on education in the 21 st century and how education systems are respond ing to them.

There have been increased calls globally for students to develop a broader set of skills during the years of formal education than in the past. Education has typically been seen as a preparation for adulthood and its work-related responsibilities. Recently, however, the focus on academic, vocational, and technical skills (e.g., Brewer, 2013) has shifted toward an aspiration for education to inform both work and life more generally (e.g., Pellegrino and Hilton, 2012). Many frameworks describe the skills or competencies that this 21 st century world demands (e.g., Binkley et al., 2012: Lippman, Ryberg, Carney, and Moore, 2015), and in so doing, they display strong commonalities. need to function effectively in society, with description
varying from very high level (e.g., Delors, 1996) to very detailed (e.g., Binkley et al., 2012). Differences also emerge primarily in the degree to which skills or competencies alone are identified or whether a wider range of human characteristics are included. The adoption of the Sustainable Development Goals (United Nations, 2016) acknowledges this shift in the focus of education toward a broader approach. Of particular interest for Skills for a Changing World, Sustainable Development Goal 4 calls for skills beyond literacy and numeracy-including readiness for primary education (4.2), technical and vocational skills (4.4), and skills needed to promote glabal citizenship and sustainable development (4.7). These targets signal an emphasis on the breadth of skills necessary to prepare children youth, and adults comprehensively for 21 st century citizenship and life.

Notwithstanding the strong endorsement of the need for a broader range of skills by global and regional organizations and by individual countries (e.g., Care and Luo, 2016: Reim and Luo, $2016 ;$ considerable variation in how national stakeholders are responding. This Skills for a Changing World: National Perspectives and the Global Movement report summarizes country-level responses based on a public scan of education systems and discusses country-level stakeholder views on the skills students 
Every country is at a different stage of evolution in its education development, and implementation of its education system varies not only according to substantive education issues but also according to national pressures and imperatives.

need for today and tomorrow in four countries: Mexico, South Africa, Kenya, and the Philippines. Although there is consistency worldwide in views about the

skills and characteristics the youth of today need for the future, counties vary greatly in implementing new approaches to education. In addition, specific country conditions influence stakeholder perceptions of how education systems are responding and providing for future generations

Every country is at a different stage of evolution in its education development, and implementation of its education system varies not only according to substantive education issues but also according to national pressures and imperatives. Our interest in the Skills for a Changing World country-level work is on how the interdependent functions of curriculum, assessment and pedagogy are drawn on to promote breadth of skills. Each function needs to act in a complementary way to provide children with the opportunity to learn. In this report we briefly review the evidence abou impact of the breadh of skils phenom these - the curiculum - through a mapping visulzation. We ask about the integration of breadth of skills through the layers of vision statements and curriculum documentation. Then, we discuss survey data that reflect the context in which education takes place and draw on the conceptualization of the learning environment presented in the Skills for a Changing World report How Educetion Systems Approach Breadth of Skills (Care and Anderson, 2016). The survey data provide pictures of the contexts upon which the educational visions will affect.

\section{VISUALIZING THE BREADTH OF SKILLS MOVEMENT ACROSS EDUCATION SYSTEMS}

An initial scan of 102 countries was undertaken to investigate the degree to which breadth of skills is reflected in national education policies and curricula (Care, Anderson, and Kim, 2016). Updated late in 2016 to a total of 113 countries, findings indicated a major shift in aspirations for how education should equip students for the future (Figure 1). However, the scan also have adopted a breach of skils approach, the age to which the approach is reflected through the different levels of education systems varies greatly. Four sets of information were drawn upon from national education websites to populate the scan:

\section{Figure 1}

The global movement

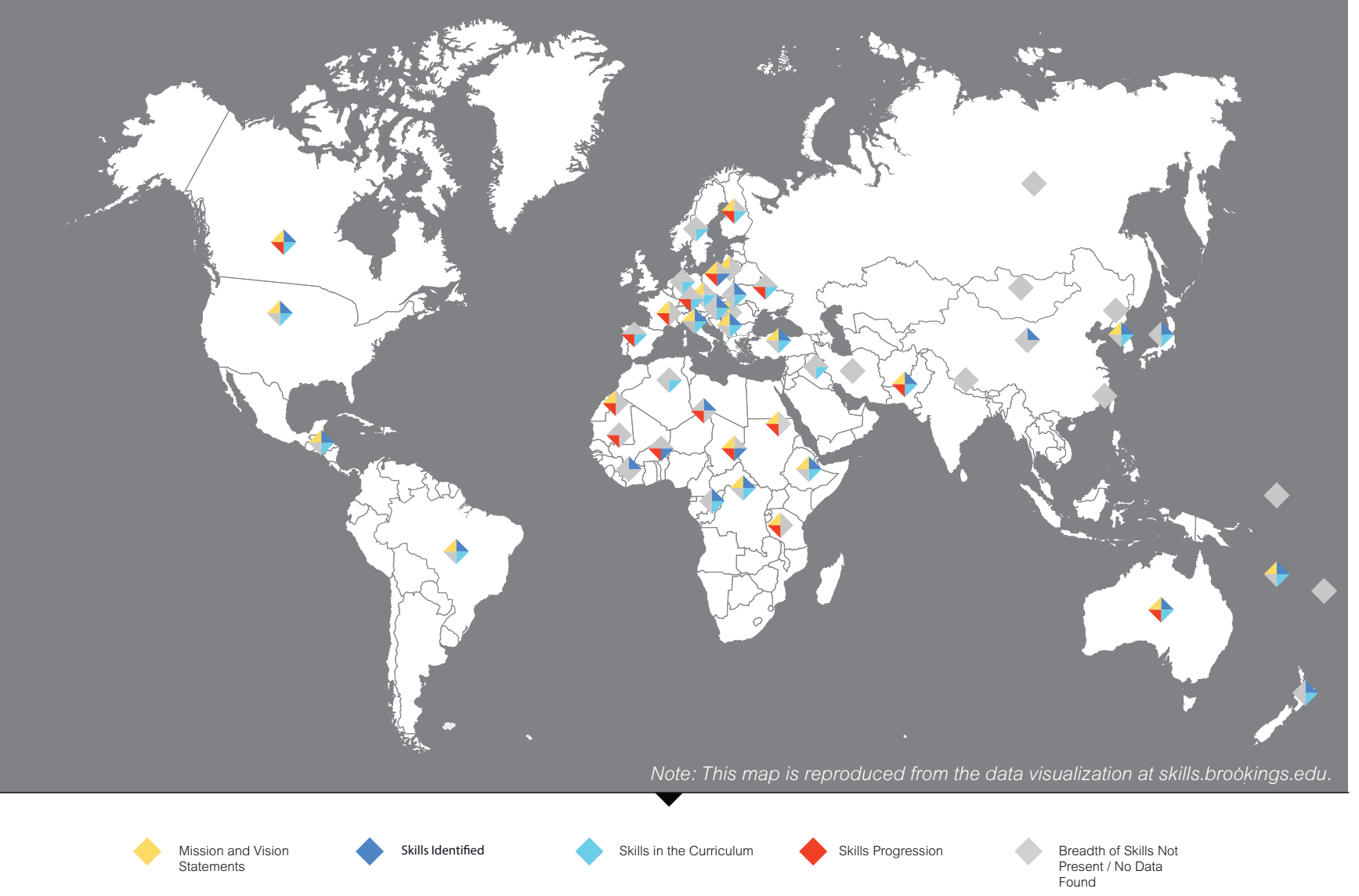

1. National education mission or vision statements.

For example, skills were mentioned in about 40 percent of the countries' vision or mission statements 2. The specific competencies or skills identified by the and in about 55 percent of their curriculum mission statements. documents. In addition, around 12 percent of the countries cited progression of these skills across

3. Evidence of integration of skills in curriculum docu- multiple age groups and subjects. This suggests that ments.

4. Evidence of assumptions about skills progressing in sophistication. countries aroups and subjects. This suggests that of skills, at leastin terms of aspirtional statreadts reflectin a reflected in policy documents. However, only a few countries are consistently identifying skills at both policy and practice levels. Practice levels would include, for example, details about how skills might be Specific skills were cited somewhere in the online documentation of about 86 percent of the countries. 
of curricula that might take the form of a description of how skills might be acquired and progress from simple to more sophisticated forms.

In terms of identifying possible patterns in a country's interest in skills, presence across all four catego-

ries of information is hypothesized to demonstrate a ries of information is hypothesized to demonstrate a comprehensive approach to planning and might be
seen as indicative of progress in implementation of seen as indicative of progress in implementation of a
skills shift in education. For this reason, the pattern of skills shift in education. For this reason, the pattern of
findings within countries is of interest. Notwithstanding that the categories of information could be identi-

fied across the countries, the style and depth of that information varied widely. Countries variously identified their aspirations as mission or vision statements, for example. For the "skills identified" category, there were differences in specificity of identification of the skills. For "skills in the curriculum," some countries provide detail across elementary and secondary education, while others mention skills within and across particular subject areas. For "skills progression," some countries provide acknowledgment of the fact that skills vary from very basic to proficient while others provide examples of how the skills progress. Associations across the categories were explored. Based on calculation of phi correlation coefficients (Table 1), "skills identified" is positively related to "skills in curriculum" ( $r=$ $0.59)$ and "skills progression" $(r=0.20)$, and "skills in curriculum" and "skills progression" are positively related $(r=0.35)$. The association between incorporation of "skills in cu nd identification of "skills progression" is seen as the strongest evidence of integration of this learning and teaching perspective into education. Of course, there is obviously a hurdle requirement in that skills must be identified in order to be integrated into curriculum, or to have been considered in terms of natural learning progressions.

From an Understanding by Design (Wiggins and McTighe, 2005) perspective, it is a reasonable hypothesis that a nation will identify its overarching educational mission and then track the implications of this back-

\section{Table 1}

Associations between identification of skills across categories

\begin{tabular}{lllll}
\hline & 1 & 2 & 3 & 4 \\
\hline 1. Vision/Mission Statement & - & & & \\
2. Skills Identified & 0.20 & - & & \\
3. Skills in Curriculum & 0.21 & 0.59 & - & \\
4. Skills Progression & 0.14 & 0.20 & 0.35 & - \\
\hline
\end{tabular}

4. Skills Progression

ward through more detailed levels of identification, curriculum embedding, and exploration of the nature of the skills themselves, such that their developmental trajectories can be linked with teaching and learning The pattern across the four categories that would support this hypothesis is that any country that identified a "skills progression" would necessarily have also populated the earlier three categories; that any country that provided information about "skills through the curriculum" would necessarily also have populated the earlier two categories; and that any country that identified "specific skills" would necessarily have commensurate "vision or mission statement." The " ising, although not su comprehensively.

The scan establishes conclusively the ubiquity of the breadth of skills movement through education systems. However, it is very much a work in progress. Many countries do not yet delineate how skills are expected to align with curriculum, nor do they include expectations for how these skills are to develop and mature, in the way they do for traditional subjects. More detail about the scan is available in Care, Anderson, and Kim (2016).

\section{Figure 2}

\section{The learning environments}

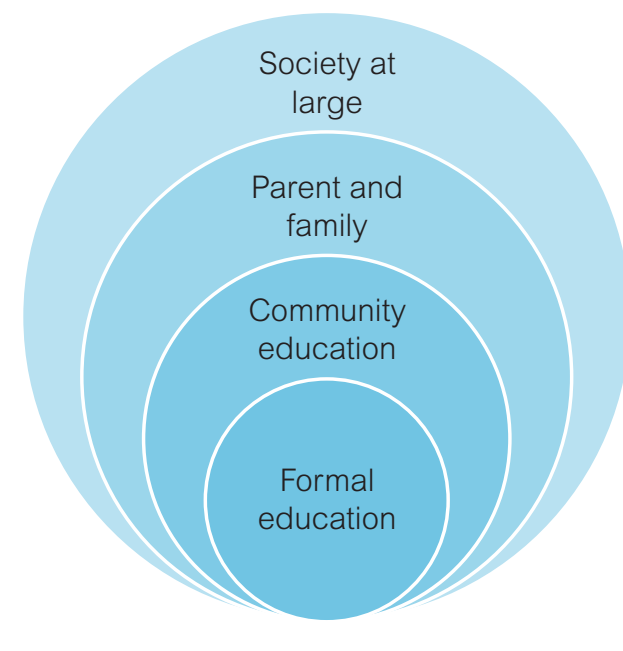

Source: Care \& Anderson, 2016.

\section{PERCEPTIONS AND ATTITUDES OF STAKEHOLDERS IN THE LEARNING ENVIRONMENT}

The context in which education and, more specifically, curricular change is occurring is both a practical and political consideration for education systems. In the report How Education Systems Approach Breadth of Skills (Care and Anderson, 2016), we described the student learning environment (Figure 2) as one in which the child spends the least time in the most structured learning environment (formal education, such as "the classroom"), and the most time in the least structured environment (society at large).

Each student's learning environments affects his or her understanding of what is important and what is valued; of course, what is important and valued would ideally be reflected through all learning environments. Accordingly, it is important to understand the attitudes and perceptions of those who populate each of the learning environments. To explore this issue, qualita- tive surveys were undertaken in Mexico, South Africa, Kenya, and the Philippines. Common to the countries is the recent extension of mandated years of formal education (South Africa and the Philippines) or inclusion of a more explicit focus on generic skills beyond the traditional academic ones (Mexico, Kenya, and the Philippines). Each country is at a different stage in the reform, with South Africe recently mandating its

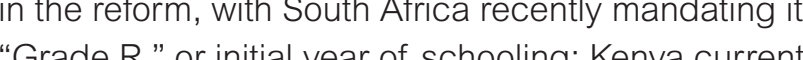
"Grade R," or initalyear of schooling, Kenya curren planning its education reform; Mexico announcing inclusion of social-emotional skills for 2017; and the Philippines having introduced its $\mathrm{K}$ to 12 reform in 2013.

Large-scale education reform is led by the formal education system. Therefore, the reform tends to be very visible and can be politically challenging. Where it has immediate economic effects, such as when additional years of schooling become compulsory or even where they merely become available, societal response can have political consequences. Where the reform implies a shift away from traditional academic achievement, hose who have benefied from the traditionat syste those who have ben thed from the traditional system in the past might push back against the change, aga with political consequences. These are the contexts within which the survey of attitudes and values of stakeholders took place in the four countries. Although a move toward breadth of skills might itself be similar across countries, the individual context of each influences responses to that move.

Life is exponentially more complex than it used to be, and thriving in the 21 st century requires a wider rang of skills than what was regarded as sufficient in the past (Dede, 2007; Kalantzis and Cope, 2008). Considering the societal and economic changes taking place globally, education needs to equip young people with globally, education needs to equip young people with ceed (Ananiadou and Claro, 2009; Trilling and Fadel, 2009). These skills go beyond the traditional academic skills of numeracy and literacy to a broader set that includes interpersonal, intrapersonal, and technologica 
skills (Casner-Lotto and Barrington, 2006). Such skills are not new; however, there is a need for mastery of different kinds of knowledge, ranging from facts to complex analyses. Critical thinking and problem solving, for example, have been components of human progress throughout history, from the development of early tools, to agricultural advancements, to the invention of vaccines, to land and sea exploration (Rotherham and Willingham, 2 (Rothenhm and Wilingam, 2010), but the extent to made explicit is much greater today.

Teachers and parents are key agents in stimulating the developm Teachers' and parents' attitudes and perceptions also contribute to children's interpersonal and academic success (Denham, Bassett, and Zinsser, 2012). At the same time, teachers and parents themselves are influenced by political and historical factors, cultura and community factors, and the physical environment. Therefore, to understand how students can be equipped with a broad range of skills beyond the traditional acad system, the atic tes and percepions of key stakeholders from the community to the political level need to be explored. Including those stakeholders might open the doors to understanding attitudes and mindsets toward a broad development of skills. Moreover examining stakeholders' attitudes and perceptions across multiple countries can be us ful for understanding the dif collectively may have toward development of a breadth of skills.

\section{STUDY AIMS}

The main research question that guided the study was "What are the perceptions and attitudes of key stakeholders toward the development of breadth of skils among school-age children?"
Interviewers and focus group facilitators used a series of probes to explore this question. They queried what types of skills should be enhanced through educatio and what types are necessary for life success. According to stakeholder group responsibility, associated issues about appropriate strategies for teaching and development of skills were explored. The following country sections are based entirely on the views expressed by study participants. Country context information is provided in order to situate these views.

\section{METHOD}

A qualitative research design with a phenomenologica strategy of inquiry was employed (Creswell, 2014). Using this strategy, the study contextualized the broad research question within the daily lives of the various stakeholders (e.g parents, teachers, school adminisof parts and nationaleves) to explore ther atudes toward and perceptions of the development of a broad rang of skills among school-age children.

\section{Data collection}

Across the four countries, data collection began in July 2016 and finished in December 2016. Two methods of data collection were employed: focus groups and indepth individual interviews. Focus groups are carefully planned group discussions facilitated by the researcher or a moderator (Peek and Fothergill, 2009). The purpose of this method is to gain understanding of experiences and concepts related to the topic of the research through interactions, and shared or opposing opinions of the participants (Morgan, 1996). Structured in-depth individual interviews involve a process wheraby the researcher asks the participants quesWions about a phenomenon in which they have experise or insight. This allows the researcher to probe and clarify information in more detail than would be possible in a focus group discussion (Creswell, 2014).

\section{Participants and sampling}

Participants for the study were chosen using purposive sampling. Participants from multiple levels of the system, from community members, to teachers, to administrators, to representatives from nongovernmenal organizations (NGOs), to policymakers, are included in the study as experts with inside knowledge of e education system of each country. Table 2 shows he number of focus group discussions and individual interviews conducted in each of the four countries.

\section{Data analysis}

Once the data had been collected through video and audio recordings and transcribed verbatim, the transcripts were uploaded and coded using either a software package for qualitative analysis (Atlas.ti' in South Africa: NVivo² in Kenya) or by hand (Mexico and the Philippines). In each country, a multidisciplinary eam of at least three researchers, with extensive background in qualitative analysis, educational psychology, or communication sciences, used inductive content analysis to explore the themes that emerged

\section{Table 2}

The number of focus group discussions and individual interviews conducted in each country

Focus group discussions

Parents from urban and rural areas

Teachers-elementary/primary

Teachers-middle school/secondary

Early Childhood Development (ECD) community members

rom urban and rura

School administrators/principals

Teachers of teachers/teacher trainers/tutors/lecturers

Young adults

Non-governmental organizations (NGOs)

Individual in-depth interviews

Policymakers and representatives in Nationa

Department of Education (DBE) or Ministry of Education (MOE)

Representatives from curriculum department

County directors of education/district superintendents

Representatives from teachers' unions and associations

Representatives from non-governmental organizations (NGOs)

Representatives from teacher training institutions
Mexico South Africa Kenya Philippines

$\begin{array}{llll}2 & 2 & 2 & 2\end{array}$

in

$2-2$

-

$\begin{array}{lll}2 & 2 & 2 \\ 0 & 2 & 1\end{array}$

$\begin{array}{lll}1 & 0 & 0 \\ 1 & 0 & 0\end{array}$

Mexico South Africa Kenya Philippines

$\begin{array}{llll}5 & 5 & 2\end{array}$




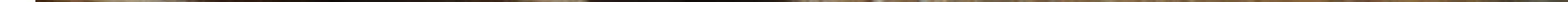




\section{Skills}

21st century skills
Collaboration
Communication
Creativity
Critical/analytical thinking
Curiosity/inquisitiveness
Decisionmaking \& reasoning
Leadership
Listening
Problem solving
Self-awareness
Self-regulation
Social/interpersonal
Teamwork skills
Technology and computer
Academic skills
Language/literacy
Numeracy
Science
Character traits
Adaptable/flexible
Confident
Disciplined
Independent
Proactive/assertive/productive
Responsible
Workforce \& society characteristics
Citizenship/nationalism
Cultural/moral/spiritual values
Entrepreneurial skills
Life skills
Mentorship
Socialization
Technical/vocational

\section{Success}

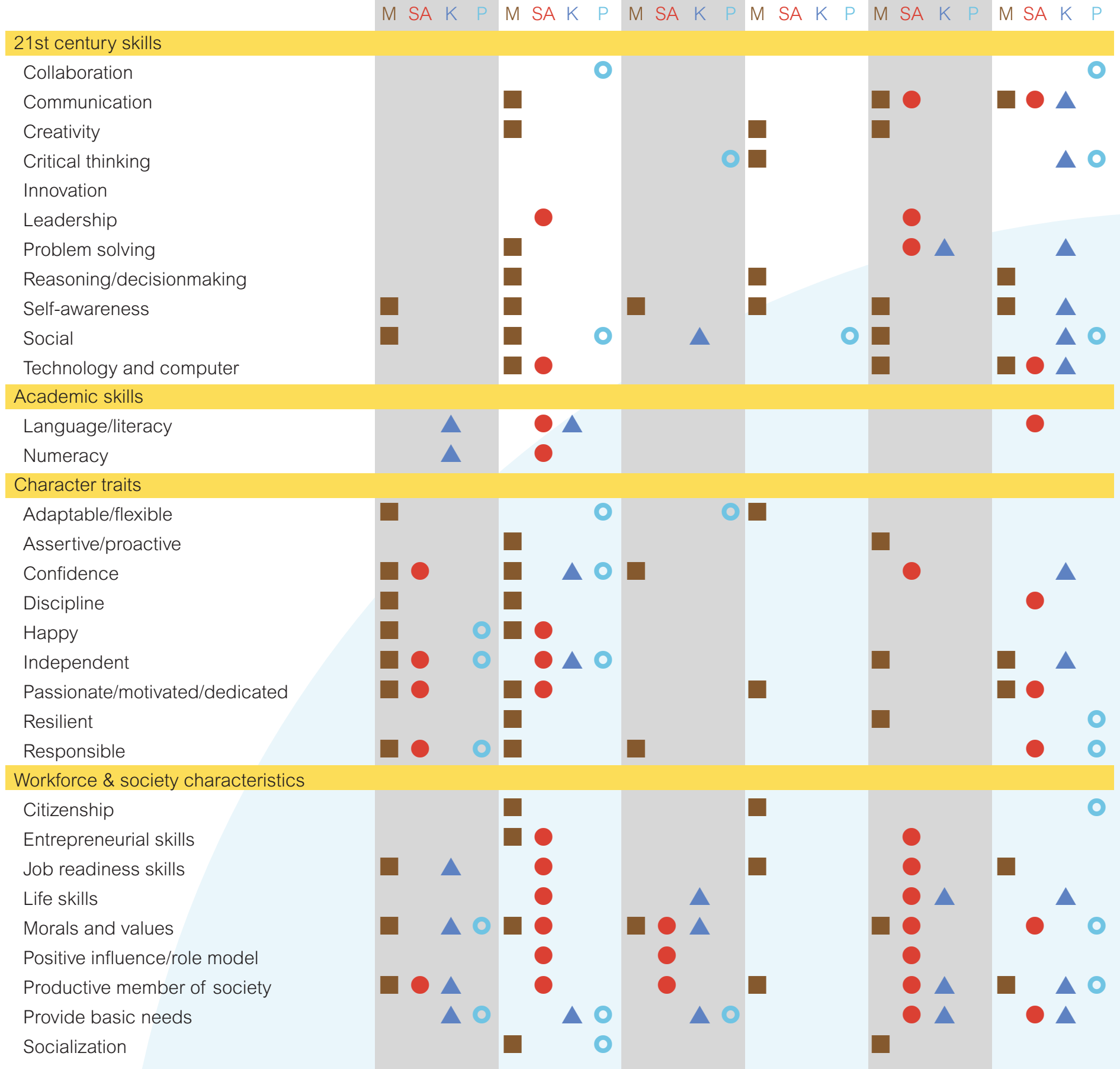


totaled \$26 billion in 2015, over 2 percent of gross domestic product (GDP). The unemployment rate in 2014 was 4.3 percent (World Bank, n.d.), and 46.2 percent of the population was below the poverty line (Consejo Nacional de Evaluación de la Política de Desarrollo Social, 2014). The 2015 Intercensal Survey by the INEGI reports that 21.5 percent $(25,694,928)$ of the population- 48.7 percent men and 51.3 percent women - self-describes as belonging to an indigeno culture, with the largest percentages in the states of Oaxaca, Yucatán, Campeche, Quintana Roo, Hidalgo, and Chiapas. About 6.8 percent of the population speaks an indigenous language, and almost a million people do not speak Spanish (OECD, 2013).

\section{EDUCATIONAL BACKGROUND}

Participation in early childhood education differs considerably by age, with 43 percent enrollment among 3-year-olds in 2014, rising to 89 percent among 4-yearolds (OECD, 2016b). Enrollment has risen substantially in the last decade in primary and lower secondary education, with 100 percent of children ages 5-14 enrolled in school in 2015. In upper secondary education, gaps exist in enrollment, graduation, and performance: Only 56 percent of 15- to 19-year-olds are enrolled in school (OECD, 2016b), upper secondary graduation is at 47 percent, and only 23 percent of 25 to 34-year-olds attain tertiary education (OECD, 2013).

In the 2015 Programme for International Student Assessment (PISA), Mexico performed below the Organisation for Economic Co-operation and Development (OECD) average in science, reading, and mathematics. The cumulative expenditure per student age 6 to 15 was $\$ 27,848$, which is 31 percent of the OECD average, whereas Mexico's per capita GDP $(\$ 17,315)$ is 44 percent of the OECD average (OECD 2016a). is 44 percent of the e poor: according to the 2014 Educational Census, 48 percent of public schools lack drainage systems, 31 percent have no access to potable water, 12.8 percent are without bath- room facilities, and 11.2 percent do not have electricity (Esquivel, 2015).

The Mexican education system is divided into basic (which includes preschool, primary, and lower secondary), upper secondary (for 15-17 year olds), and higher education (INEE, 2016b). The three levels of basic education are mandatory. Elementary (primary) schoo was established as obligatory in 1934, middle school (lower secondary) in 1993, and preschool (pre-primary) in 2004 (INEE, 2014b). Upper secondary education was made compulsory in 2012 (OECD, 2013).

Traditionally, the education system in Mexico has been quite vertical and prescriptive (SEP, 2016), favoring the transmission of content over the unders rstanding f complex concepts that could lead to developing students' potential, creativity, and ability to create new knowledge (Cárdenas, 2016). In February 2013, President Peña Nieto signed the Education Reform Bill, amending two articles of the Mexican Constitution to set the legal bases for a teacher evaluation system by, among other things, creating the Instituto Nacional para la Evaluación de la Educación (National Institute for Educational Assessment) (INEE, 2016a).

To ensure all individuals' access to education in a diverse society with varied conditions, the Mexican modalities to address different contextual realities (INEE, 2014a). The teaching context and pedagogic needs of modalities other than regular schooling are different, as well as more challenging. For example, indigenous schools aim to be bilingual as well as to strengthen knowledge and skills related to their ethnic group. Community schools are intended for locations with fewer than 100 inhabitants and for migrant populations. Telesecundaria-created in the 1960s to address hard-to-reach areas but nowadays also present in some urban locations-is taught through videos, televised modules and satellite.

\section{THE 2016 EDUCATION MODEL}

In 2016, the SEP released a new curriculum model for all levels of mandatory education. The basis for changing the education model was related to: 1) greater social/global complexity; 2) the recognition that learning in the previous model and the need for flexibility and creativity; 4) an expansion of mandatory education to include upper secondary; and 5) a lack of common learning criteria (SEP, 2016).

The model represents a shift from a vertical approach to one that is more horizontal and is built around five axes: school at the center (autonomy); curricular approach; professiona teacher developr and equit; and governance of the educato (SEP, 2016). Seven domains of learning are emphasized: 1) language and communication; 2) critical and reflective thinking; 3) values, interpersonal skills, and collaboration; 4) physical and emotional development; 5) Mexico and the world; 6) art and culture; and 7) the environment. Three components of the curriculum the interact with one another to enhance an integrated learning approach are key competencies, individual and social development, and curricular autonomy.

Teacher training and development is another key component of the model. This includes professional development based on merit; improved teacher training and links between teacher colleges and the schooling system; teacher evaluation related to training and incentive systems; and continuous professional development including in-person and distance training.

\section{CURRENT EDUCATIONAL CONTEXT}

Overwhelmingly, nearly all stakeholder groups (Table 2) included in the study noted the need for students to learn a wide variety of skills to be successful in school, as an adult, and for work. Socio-emotion skills, both related to self (e.g., self-esteem, self-reg- ulation, self-confidence, self-awareness, and self-accountability) and in relation to others (e.g., communication, empathy, respect, sociability, and honesty), surfaced predominantly, in particular among parents and teachers. Other skills highlighted, though to a lesser degree, included executive processes, such as perseverance, discipline, motivation, and organization. Critical thinking and problem solving skills were consideredimportant considered mportant by secondary school teachers. eacher trainers, key opinion leaders, and governme policymakers, but notably not mentioned by the other stakeholders. Imagination, creativity, and happiness were mentioned across all stakeholder groups. Only teacher trainers mentioned technology. Notably, traditional skills such as reading, writing, and mathematics were not mentioned as important for success. This could be a reflection of an increase in the awareness of the wider range of skills and an implicit understanding that the traditional skills are necessary. Abadzi (2016) suggests that the emphasis on complex skills could be due to memory bias, since complex skills in fact rely on a strong foundation of basic components. The education reform and the recent announcement of the new Education Model, which happened to coincide with the research conducted for this study, highlight the importance of a breadth of skills with an emphasis on socio-emotional skills (Excélsior, 2016; Milenio, 2016). Alternatively, the responses could be a reflection of a longer-standing and growing perception that 21st century skills are critical to success.

When asked which skills should be taught to children today, most stakeholder groups mentioned a broad range. Traditional skills were cited by parents, school administrators, key opinion leaders, and policymakers but notably not highlighted by teachers. Parents more often described socio-emotional skills as innate and not teachable and placed a greater emphasis on cognitive skills, which may be due to a lack of undercognive skils, which may be due to a lack of understanding about what socio-emotional skills are. Amon teachers, there seemed to be a correlation between rising grade level and the complexity of other skills 
that should be taught. For instance, early childhood educators emphasized "learning to live together" while secondary teachers stressed conflict resolution. Teamwork came across as a key skill that should be taught in school. Critical thinking, analytical thinking, reasoning, logic, and problem solving skills also came across more strongly in this portion of the study relative to the questions about success in general.

Broad discussions around the links between how schools prepare children for work noted an importan disconnect between what has been taught in pas decades and what the labor market demands. This related to both the quality of teaching and the breadth of skills being taught. An increase in access to schooling was noted, but at the cost of achievement and enormous disparities across socio-economic strata, urban and rural areas, and among marginalized groups, in particular indigenous populations. In addition, a link was suggested between the problem of youth who are neither attending school nor working and the persistence of inequalities and crime in Mexico.

Both formal and informal learning environments were mentioned as places where skills can be acquired. Besides school, the home environment featured prominently, with some discussion on the importance of linking learning at school to the home. It was suggested that regular communication between teachers and parents could help facilitate that learning. Other potential areas of learning mentioned included parks, the streets, and the community. Television and other media were cited as potential positive as well as negative influences. Clubs, sports teams, or other community organized activities did not feature prominently in the discussions.

\section{CHALLENGES TO DEVELOPING A} BREADTH OF SKILLS IN CHILDREN

Numerous challenges were mentioned related to the ability of the education system to equip children with the skills they need for the future (Table 4). Most of those challenges related to structural aspects of he system, including its sheer size (large number of schools) and complexity (long chains of command). Lack of resources in rural schools and a need for improved teacher training were also cited. Some of the challenges to adapt to modern demands and "a changing world" were noted to be rooted in colonia times when discipline and authoritarian, teacher-centered education systems were the norm. Several stake holder groups cited short political cycles as hampering continuity in proposed education reforms.

Much of the discussion centered on the recent education reform and the 2016 Education Model. Overal, stakeholders had a positive view of the model, but great deal of concern was expressed around its implementation-in particular, considering the upcoming election cycle in Mexico and fears that a new party in power could nullify the plan. Concerns around implementation included a contradiction between the breadth of the proposed competencies to be taught in schools and the competencies being examined in learning assessments. Teachers noted that students are measured on their cognitive development rather thent rather than on other competencies and that the success of teachers is thereby also measured in terms of students' cognitive achievement. According to some stakeholders, this results in little room for creativity and flexibility for teachers who are forced to "teach to the test," and students who are unable to develop individuality In addition, teachers and administrators said they were discouraged by many years of varisaid they were dlscouraged by many years of var ous education reforms leaving them skeptical to real possibility of change and improvement. Government policymakers noted the critical importance of modifying teaching practices in order to achieve the goals of the model and different assessment methodology, such as formative assessments. Aligning curricula with local contexts and needs was suggested as a way to engage both teachers and students.
Overcrowded classrooms, lack of respect from students, and insufficient support and participation from parents were also named as obstacles to implementing the model. Furthermore, policymakers highlighted an insufficient link between school curricula and the demands of the labor market. Other challenges related to the demand side included huge variance in the needs of students due to heterogeneity in the

Mexican population in terms of culture, language, and socio-economic status. Stakeholders suggested that greater engagement of parents could help to address some of these challenges. Parallel initiatives such as anti-poverty programs or school-feeding programs could help address issues such as children arriving at school hungry.

\section{Table 4}

\section{Challenges and concerns of the education system in Mexico by stakeholder group}

Categories Parents Teachers $\begin{gathered}\text { School } \\ \text { administrators }\end{gathered} \begin{gathered}\text { Teachers of } \\ \text { teachersl } \\ \text { trainers }\end{gathered}$
General concerns and challenges
Resource/funding
Teacher training
Involvement
Working conditions/
poor infrastructure
Larger context
Current curriculum concerns and challenges
Teacher-centered
Exam-oriented
Too congested
New curriculum concers




\section{CONCLUSION}

It appears that priorities have shifted substantially in the Mexican education system from aiming to achieve full national coverage for all elementary school children to focusing on ensuring quality by providing children with the skills they need to become productive adults in a changing and challenging world.

In the past, the push to achieve universal enrollmen led to the hasty training of teachers-making a verti$\mathrm{cal}$, hierarchical structure and the transmission of content a priority over understanding complex concepts (SEP, 2016). Furthermore, education favored emphasis on Spanish and national history that would promote strong national identity and encourage obedience over critical thinking and self-expression. The education system has tended to be prescriptive, and teachers have played a very central role as the "owners of knowledge" who have the responsibility of transmitting it. These practices still prevail in many schools and in educators' teaching styles, hampering the implementation of new me paradigms.

As an effort to respond to the needs of an evolving society that bolsters democratic values, aims to form participative citizens, and is part of a globalized world, different reforms and adjustments were made to the education system from the early '90s geared toward developing competencies. Much of the reform activity st Modernizing Basic and Normal Educalon, signed in system, reformulating the curriculum, and revaluing the teaching profession (OECD, 2010; Zorrilla, 2008). Teachers expressed the view that the image and expectations of teachers have changed significantly and many teachers are having a difficult time finding their new rolei to information through the media and communication technologies, depriving teachers of being the sole "holders of knowledge." Apart from having an impac on the perceived value of formal education, access to information also strongly affects teachers' images. Teachers expressed the view that students often do not look up to them as easily or as much as before, thus making it more difficult to engage children in the learning process.

The reforms and adjustments made to the educaional plans in the last 25 years expected educators to modify their teaching from a more traditional style and to provide students with opportunities to develop competencies. However, these strategies often fell short. Stakeholders from across the different segments reported a lack of clarity about what the key compeencies are and, particularly, a lack of concrete tools to help teachers get their students to develop them. They also noted that there is a gap between the theory and how to anchor competencies to students' everyday reality to make them meaningful and useful. Teachers say this contributes to lack of motivation and purpose of going to school.

Among the sample of policymakers, educators, academics, and civil society interviewed in the study, there was a great deal of knowledge about the concept of breadth of skills as well as the relevance of these skills to students' current and future life, but there were disconnects between the concept, how to achieve it, how it will lead students to attain their goals at a personal level, and how this will contribute to the country's dether man stakeholders "skills" still seent (applying and deviloping seemed already considered in the education programs would be more important than adding new ones.

For parents, the concept of skills was even more abstract; they tended to perceive socio-emotional capabilities and executive function skills as innele ablhathat can be improved or perfected but not taught. Parthat can be improved or perfected but not taught. Parents often defined these as values or personal qualities they want to see their children have or would like to instill in them. However, these types of capabilities or qualities were not seen as part of their children's chievements at school: grades and achievement on ests appeared to be more important. Additionally, parents still expected educators to transmit knowledge and did not see their children or themselves being an active part of the learning process.

Major hurdles remain in implementing the new Education Model in the classroom. These include cultural values, the size and complexity of the educationa system, the diverse and inequitable conditions in the country, and teacher quality and pre-service training reform. Nevertheless, the understanding and recognition of the need for acquisition of the breadth of skills across stakeholder groups surveyed for this study illuminate the opportunities in Mexico to make great system and for future generations.

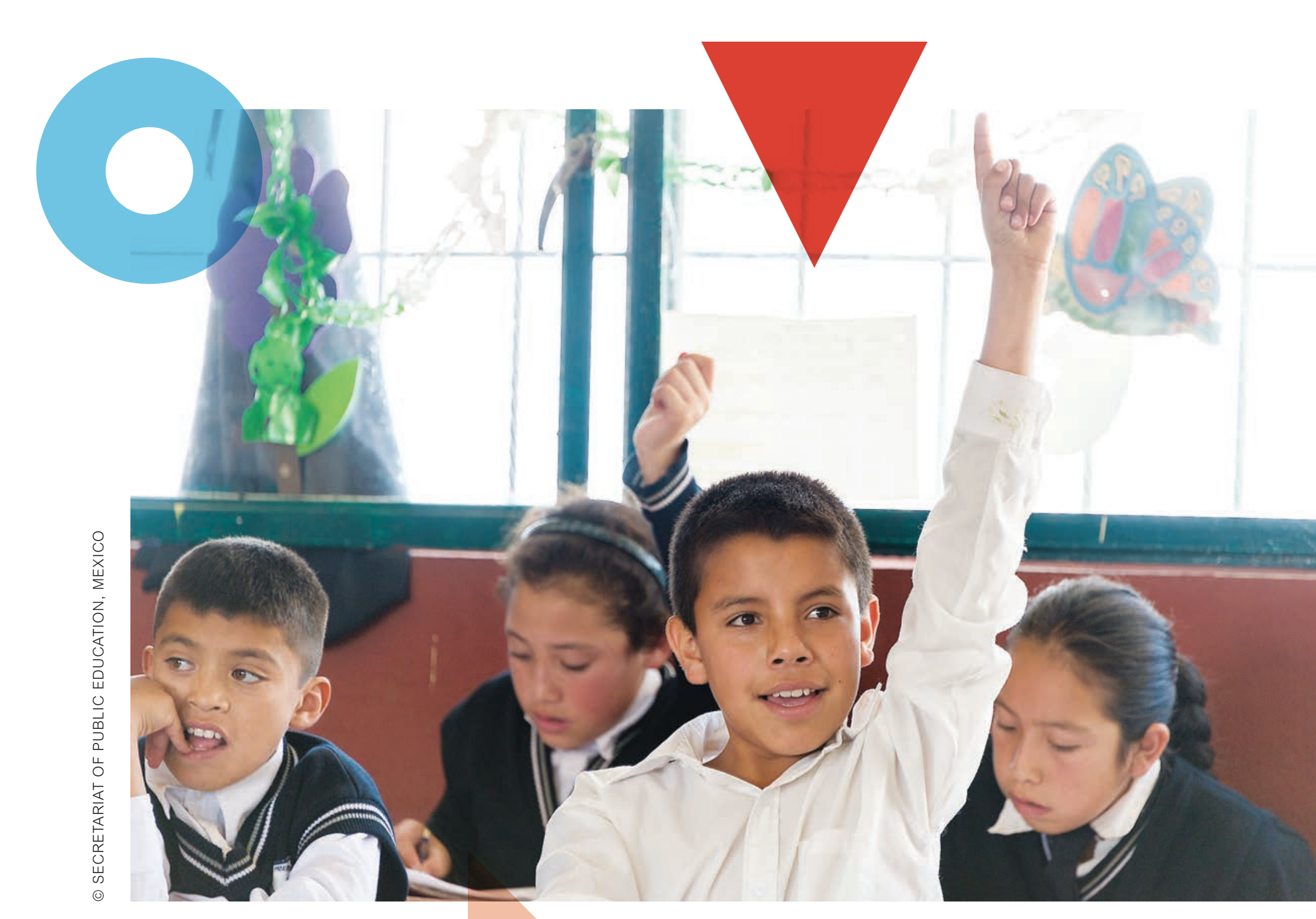




\section{South Africa}

\section{COUNTRY EDUCATIONAL CONTEXT}

The adoption of the Constitution of the Republic of South Africa (Act 108 of 1996) provided a basis for curriculum transformation and development in the country. The educational vision "is of a South Africa in which all our people will have access to lifelong learning, education, and training opportunities, which will, in turn, contribute towards improving the quality of life and buiding a peaceful, prosperous, and democr life South Africa" (Departh South The education agenda in South Africa is to provide access to quality education for all children and to provide holistic development of young people that better prepares them for life and work opportunities after they leave school. The Action Plan to 2019: Towards the Realisation of Schooling 2030 has 27 goals that are Realselion of Schooling 2030 has 27 goals that are with emphasis on five prionities (Department of Basic Education, 2015):

1. Improve the access of children to quality early childhood development (ECD) below Grade 1.
2. Improve the professionalism, teaching skills, subject knowledge, and computer literacy of teachers throughout their careers.

3. Ensure that every learner has access to the minimum set of textbooks and workbooks required according to national policy.

4. Ensure that the basic annual management processes take place across all schools in the country in a way that contributes toward a functional school environment.

5. Improve the frequency and quality of the monitoring and support services provided to schools by district offices, partly through better use of education.

Education policy in South Africa is equity-driven as it strives to undo apartheid's legacy of inequity. The 1994 transition from apartheid was a starting point for the Department of Education to recalibrate its goals and policies to remedy the country's deep racial 
and geographic inequities. Since 1994, the national curriculum has undergone three major reforms, and the government has reallocated funds, resources, and human capital with the intention of creating an equitable education system —one that not only propels the high achievers but also supports under-resourced communities. In terms of curriculum delivery, there is an emphasis on structure and effective teacher training. In terms of content, there is a recognition of both academic achievement in core subject areas of language and mathematics, and the development of nontraditional skills that lead to a meaningful contribution to society (Jansen and Taylor, 2003).

\section{DEMOGRAPHIC AND SOCIO-}

\section{ECONOMIC BACKGROUND}

South Africa is a diverse country with people of many different origins, cultures, languages, and religions. According to the 2016 Community Survey, the population was estimated at 56 million, of which about 28 million (51 percent) are female (Statistics South Afric 2016). The country's population is 81 percent black African, 8 percent white, 9 percent colored ${ }^{3}$, and 3 percent Indian/Asian. About 65 percent of the population is urbanized, living in one of three main centers of Johannesburg/Pretoria in Gauteng province, Cape Town in Western Cape province, and Durban in KwaZulu-Natal province (Statistics South Africa, 2016a).

According to the Quarterly Labour Force Survey, for the fourth quarter of 2016, the official unemployment rate in South Africa was about 27 percent (Statistics South Africa, 2016d). It is notable that the unemployment rate among the black African population is highest (30 percent), while it is the lowest for the white popution (7 percent). Young people agtor 15-24 wh population (7 percen). Young peop ages 15-24 are vulherable in the labor market with an unemployment rate of 51 percent. Education plays an important role in labor market outcomes; individuals with less than 12 years of formal schooling have an unemployment rate of about 31 percent (Statistics South Africa, 2016d).

\section{EDUCATIONAL BACKGROUND}

The development and current state of the South African education system is intimately linked to its history of apartheid. In 1994, the country transitioned from apartheid to a nonracial democracy. The concep of non-racialism is unique to South Africa, roughly meaning "without reference to race"; it was used as a conceptual counter to the racist preoccupations of the former South African state (Jansen and Taylor, 2003). After decades of social and economic segregation and legislated racial exclusivity, South Africa was left with a legacy of income inequality along racial lines (Jansen and Taylor, 2003). The government prioritized education reform as an effective way to increase equality in economic opportunities and promote socia cohesion (Spaull, 2013).

During the first five years following the political transition, the government implemented systematic reforms to the educational structure. The 19 fragmented and racially, ethnically, and regionally divided department of education were replaced with a national Department of Basic Education and nine provincial education departments (OECD, 2008; Mouton, Louw, and Strydom, 2012). ment is to shape policy, determine the standards for education planning, and monitor and evaluate outcomes. The role of the nine provincial governments is to implement policy. National and provincial governments are concurrently responsible for functions such as education, health, and social welfare (Jansen and Taylor, 2003).

\section{EDUCATION REFORM}

The South African government has focused on three major areas for its reform of the education system: increased spending, teacher reallocation, and curriculum reform. Here we focus on the latter, notwithstanding the major impact of expenditure and workforce.
One of the most profound challenges the South African government faced was the rapid transformation of the school curriculum (Jansen, 2001). The first reform after the 1994 elections was to convert and combine the syllabuses of the previous 19 racially segregated education departments into a single, more effective curriculum (OECD, 2008). The new curriculum, C2005, which was launched in 1997, was intended to be a progressive model of education based on three design principles: 1) outcome-based design; 2) reframed earning areas from traditional subject disciplines to an integrated knowledge system; and 3) student-centered teaching (Jansen and Taylor, 2003; OECD, 2008 Mouton et al., 2012).

The goal was for C2005 to be implemented in Grade 1 in 1998 and in Grade 7 by 1999, in order to be phased in progressively and cover all sectors of schooling by 2005 (Harley and Wedekind, 2004; H.J. Steyn, S.C. Steyn, De Waal, and Wolhuter, 2011; Mouton et al.. 2012). Teachers were inducted into the new system using a cascade training model. District officials and educators at higher levels received initial training; they were then responsible for training at all levels until eachers at the school level were reached. As soon as C2005 was implemented, it was criticized as too complex. In addition, by the time it reached the lower levels of education professionals, the training was watered down (Jansen and Taylor, 2003; OECD, 2008); we the refre achers. Furthermore, nore privileged schools successfully implemented the gled. As a result, C2005 was seen to aggravate the inequality between schools (Jansen and Taylor, 2003; OECD, 2008)

The Revised National Curriculum Statements (RNCS) were published in 2002. The RNCS gave more emph wis to basic skils progression from one grade to the next (Jansen an Taylor, 2003; OECD, 2008; Mouton et al., 2012).
However the rapid rollout and revision of the curricuum, paired with insufficient training, caused increased confusion among teachers. Moreover, some schools still did not have the basic infrastructure, resources, or learning materials necessary to implement and support the new curriculum (Jansen and Taylor, 2003; Mouton et al., 2012). In 2010, the Minister of Basic Education again called for a review and planned for Mouton et al., 2012). Curriculum and Assessment Policy Statements (CAPS) replaced the RNCS. The goal was to prioritize quality over quantity by reducing subjects from eight to six for Grades 4 to 6. CAPS also introduced an additional language from Grade 1. which was compulsory and included extended hours for instruction (Maluleka, 2011: Mouton et al., 2012). The CAPS curriculum is perceived as a more regulated learning program that provides more time for language and mathematics. It relies on textbooks to explicitly guide the pace as well as daily and term outcomes. Teachers therefore have less responsibility to interpret and discern target student outcomes (Department of Basic Education, 2014). In 2012, CAPS was implemented in Grades R to 3 and Grade 10. In 2013, it was implemented in Grades 4 to 6 and $G$ rade 11. The year 2014 was significant as 106 and Grade 11. The yea 2014 was significant as it marked the final stage of implementation of the curriculum to Grade 12 (Department of Basic Education, 2014).

The main differences in skills and the teaching of these skills emphasized by the different curricula are summarized in Table 5 .

\section{CURRENT EDUCATIONAL CONTEXT}

In South Africa, stakeholder views for this study were captured from August to November 2016. Participants included young adults who are a couple of years out of school, as well as representatives of other groups as outlined in Table 2. 
Table 5

\section{Skills across iterations of South Africa curricula}

\begin{tabular}{|c|c|c|}
\hline Curriculum & Main skills emphasized in curriculum & Teaching of the skills \\
\hline C2005 & $\begin{array}{l}\text { C2005 focused on traditional skills, such as } \\
\text { languages, mathematics, and natural sciences. } \\
\text { However, they also included "non-traditional" } \\
\text { skills such as life orientation, problem solving } \\
\text { using critical and creative thinking, and team } \\
\text { work. }\end{array}$ & $\begin{array}{l}\text { Teachers were given free range to develop their } \\
\text { own content for each subject, as long as they } \\
\text { made sure the broad outcomes given by the } \\
\text { policy were achieved. }\end{array}$ \\
\hline $\begin{array}{l}\text { RNCS (Revised } \\
\text { C2005) }\end{array}$ & RNCS focused on similar skills as the C2005. & $\begin{array}{l}\text { RNCS was developed to give the teachers more } \\
\text { structured and understandable guidelines on } \\
\text { how they can create their content to achieve the } \\
\text { outcomes. }\end{array}$ \\
\hline CAPS & $\begin{array}{l}\text { CAPS went back to putting even more empha- } \\
\text { sis on the teaching of languages and math- } \\
\text { ematics. However, it did continue to focus on } \\
\text { "non-traditional" skills that lead to the knowledge } \\
\text { and values necessary for self-fulfillment, and } \\
\text { meaningful participation in society as citizens of } \\
\text { a free country. }\end{array}$ & $\begin{array}{l}\text { Very specific content for each subject was given } \\
\text { to the teacher. Furthermore, a more standard- } \\
\text { ized way of teaching the learners were speci- } \\
\text { fied, where children could be assessed based } \\
\text { on their knowledge gained. }\end{array}$ \\
\hline
\end{tabular}

Specific skills and other characteristics identified most frequently by the stakeholder groups are shown in Table 3. It shows consistency overall across the stakeholder groups within South Africa, and to a slightly lesser degree between South Africa and other countries. Nevertheless, some differences across the stakeholder groups in South Africa are notable and are discussed below.

Across all stakeholder groups, human characteristics primarily related to citizenship and nationalism were mentioned when discussing identification and development of skills. In addition, stakeholders frequently cited factors such as independence, confidence, self-motivation, and self-drive when asked to identify skills necessary for life success. Parents and teachers especially stressed this idea of being responsible for one's own success. However, this idea contrasts with the prevalent theme across most of the stakeholder groups of the importance of giving back to one's community. In South Africa, citizenship or being a good citizen is not separable from life success. Likewise, according to the Department of Basic Education, successful individuals are involved in their communities because, ultimately, community involvement benefits society as a whole.

Other patterns were noticeable across stakeholder groups with regards to identifying factors that charac(e.g., parents and teachers who work directly with children) focused on personal attributes and skills related future succ while stakeholders removed from the child (e.g., government policymakers) focused on skills and characteristics linked to broader societal roles. For example, parents, teachers, and school terize success. First, stakeholders close to the child
Skills and characteristics tended to coincide with the promotion of inclusion, diversity, equity, and life in the 21st century-issues that are of utmost importance in South Africa.

administrators identified success as having a sense of purpose, a vision for the future, and a good work ethic, along with setting and achieving goals and being responsible and happy. Young adults similarly emphasized happiness, supporting a family, and achieving personal goals as defining success; however, there was a tension between how they themselves defined success and how they perceived the community defines success-placing emphasis on status symbols such as handbags and big houses. On the other hand, representatives from NGOs and government policymakers identified success as having positive morals and values, contributing to society, and being aware of broader social and political events. Second, only ECD teachers and representatives from teachers unions identified specific academic skills, such as language, numeracy, and literacy skills, as defining success, while general skills such as communication, creativity, and problem solving were mentioned only by groups that are not directly working with children (i.e., policymakers). Despite mentions of the specific skills, personal attributes and characteristics were most often stated by all stakeholder groups as factors related to success.

Moving beyond factors of success to the skills deemed to be important for school-age children, communication skills, social and interpersonal skills, as well as literacy and numeracy skills were identified most often by all stakeholder groups. In addition, those closest to the child-specifically parents and teachers-were especially keen on specific skills that set a strong foundation for children and prepare them beyond school, for careers, including language (mastering both English and their mother tongue), listening, and leadership skills. Technical and vocational skills were also emphasized, especially for children who are not academically inclined. Respondents more removed from the child were more likely to identify higher-level cognitive and social skills related to the workplace, such as problem solving, critical and strategic thinking, planning and goal setting, mentorship and financial management. School administrators, in particular, most often mentioned characteristics such as respect, independence, confidence, and positive attitude as important for children.

Across all stakeholder groups, the functional aspects of skillsets and characteristics that lead to more sophisticated abilities were emphasized. Additionally those skills and characteristics tended to coincide with the promotion of inclusion, diversity, equity, and life in the 21st century-issues that are of utmost importance in South Africa. For example, communication skills were seen as the foundation across all spheres of life because they encourage agency and allow on to engage and work well with others and allow on them. them. Such abilities also allow one to express opinion and constructively argue a point of view. The ability to get along well with others is seen as vital to understanding and adjusting to other cultures. Along the same lines, technical and vocational training allows those who ar those who are not academically inclined to obtain is identified and developed and they can cotential is identified and developed and they can contribute to society. Moreover, technology and computer skills are 
seen as critical for integrating and accommodating al learners, although some expressed concerns about the heavy reliance on technology given that there are underresourced schools.

In terms of ways that skills could be developed among or taught to school-age children, parents and ECD teachers emphasized play and observational learning methods. Teachers also stressed group work, discussion, and learner-centered approaches (e.g., learning by doing). Stakeholder groups, in general, seemed to be aware of the need to move beyond traditional approaches to teaching and away from the idea of teachers as transmitters of knowledge. As such, learner-centered approaches and the need for innovative teaching methods were mentioned frequently. Teacher trainers stated that rather than using one core teaching strategy, being flexible and adapting strategies are necessary for including all learners. $S$ secondary teachers specified lecturing as an easy and common method that allows them to complete the curriculum within the school year.

Overall, stakeholder groups agreed on the environments where skills are cultivated: school, home, church, and community. However, there seem to be differences in the kinds of skills and values that are learned from those environments. Home is where attributes such as respect, discipline, responsibility, and leadership are fostered, whereas church is where morals and values are cultivated. Community and other informal environments are where technical and interpersonal skils are fostered. In addition, teachers specified media as a platorm for learning information and values.

\section{CHALLENGES FACED BY EDUCATION}

\section{SYSTEM}

Alongside identification and discussion of the valued skills, participating stakeholders at each level communicated many challenges faced by the education system generally and related to development of a breadth of skills. The challenges can be grouped broadly into five categories as shown in Table 6 .

Lack of resources and funding, as well as unequal distribution of resources across schools and provincall stakeholder groups. Parents typically referred to a lack of computers and other technology devices when discussing resources; however, they also mentioned lack of sport facilities, as did young adults. The importance of participating in sports was highlighted by parents and young adults as a mechanism for instilling good skills and values such as discipline, confidence, goal-setaddition, lack of facilities or access to these facilities can mean negative consequences such as drug and alcohol abuse, because children do not have alternative ways to spend their time. For teachers, a lack of textbooks and computers makes it difficult to implement the curriculum. Policymakers agreed that lack of resources, especially in ural areas, hinders teachers, and they were aware that resources need to be better allocated.

Related to funding issues, there are challenges concerning working conditions, which involve large class sizes (i.e., teacher-student ratios) and being overloaded with paperwork and other bureaucratic processes. This issue was mentioned only by the stakeholder groups that work closely with btudents (i.e, parents, eachers, school administrators, and young adults). According to teachers, the large class sizes prevent them from meeting the needs of each learner effectively because knowing each of them is virtually impossible. At times, controlling or managing the class was a problem, as well. Young adults, reflecting on their time in school, agreed that large class sizes made it difficult to engage in group work or receive individualized attention from teachers.

The need for more properly trained teachers was frequently mentioned as a challenge by parents, teach-

\section{Table 6}

\section{Challenges and concerns of the education system in South Africa by stakeholder groups}

Categories Parents $\begin{gathered}\text { ECD } \\ \text { teachers }\end{gathered}$ Teachers $\begin{gathered}\text { School } \\ \text { administrators }\end{gathered}$
Resource/funding
Teacher training
Involvement
Working conditions

'Note: Representatives from Teachers' Unions and Quality Control Board did not identify specific challenges ers, school administrators, and teachers of teachers. of apartheid caused many skilled teachers to exit the workforce (Spaull, 2013). Although teachers often mentioned receiving training in such areas as computer skills, numeracy, and exam marking, the training is insufficient and often not tailored to their individual needs. Teachers feel ill-equipped to teach competencies that they themselves do not have or know how o teach, such as technology and computer skills. teach, such as techno reported that students than they do, and when acsed to information resources than they do, and when asked questions, the teachers are not adequately equipped to respond effectively. The Department of Basic Education is aware of the challenges surrounding teacher workforce readiness and is discussing priorities and allocation of funds for raining teachers.

Another challenge that was mentioned primarily by eachers and school administrators was a lack of support from or active involvement of teachers, students, parents, and government. Teachers especially beTeacher rationalization reforms after the abolishment lieved that education of a child requires both teachers and parents to play a role. Lack of parental involvement creates difficulty in motivating children to learn, leading to a lack of student engagement. Also, what is being taught in the classroom is not necessarily being reinforced at home. School administrators also agreed that lack of parental involvement is a challenge; however, they also cited lack of teacher interes and support from provincial and national government as challenges. Together the lack of involvement or collaborative effort and enhanced communication among the multiple stakeholders in educating the child.

Stakeholder groups recognized that learning does not occur in isolation but that contextual factors have strong direct and indirect influences. In 2015, KwaZulu-Natal, where the study was conducted, had nearly 3 million children who were receiving child support grants and nearly 120,000 children receiving foster 37 percent of households in KwaZulu-Natal had an employed adult in the home. The home situation coucare grants (Hall and Sambu, 2015). In addition, only 
pled with high poverty rates often result in high failure rates and lower enrollment and school attendance (Hall, 2015). In addition, parents and young adults were concerned about the violence in the community and the home, and more important, children succumbing to negative pressures, such as joining gangs, promoting violence, and abusing alcohol. These kinds of home situations are challenging because learners cannot retain what is taugh in these environments, and in some households, there are no adults who can assist them with basic needs or schoolwork.

21ST CENTURY SKILLS AND THE CURRICULUM ASSESSMENT POLICY STATEMENTS (CAPS)

The CAPS curriculum is a single, comprehensive policy document that provides guidance for learning and teaching in South African schools (Department of Basic Education, 2016b). The development of skills and values is embedded within the curriculum, as its goals are to produce learners that can identify and solve problems, make decisions using critical and creative thinking, work effectively with others, critically evaluate information, communicate effectively and show responsibility toward the environment and others.

We are trying to get people to not only to close their assessment at level one, which is what can you see, but rather to get them to kind of ask children questions that would provoke thinking and thinking more creatively. We are trying to do that, and we are trying to insist the way we measure what it is they are doing is more than on their performance around lower order thinking but also on higher order thinking. representative Department of Basic Education

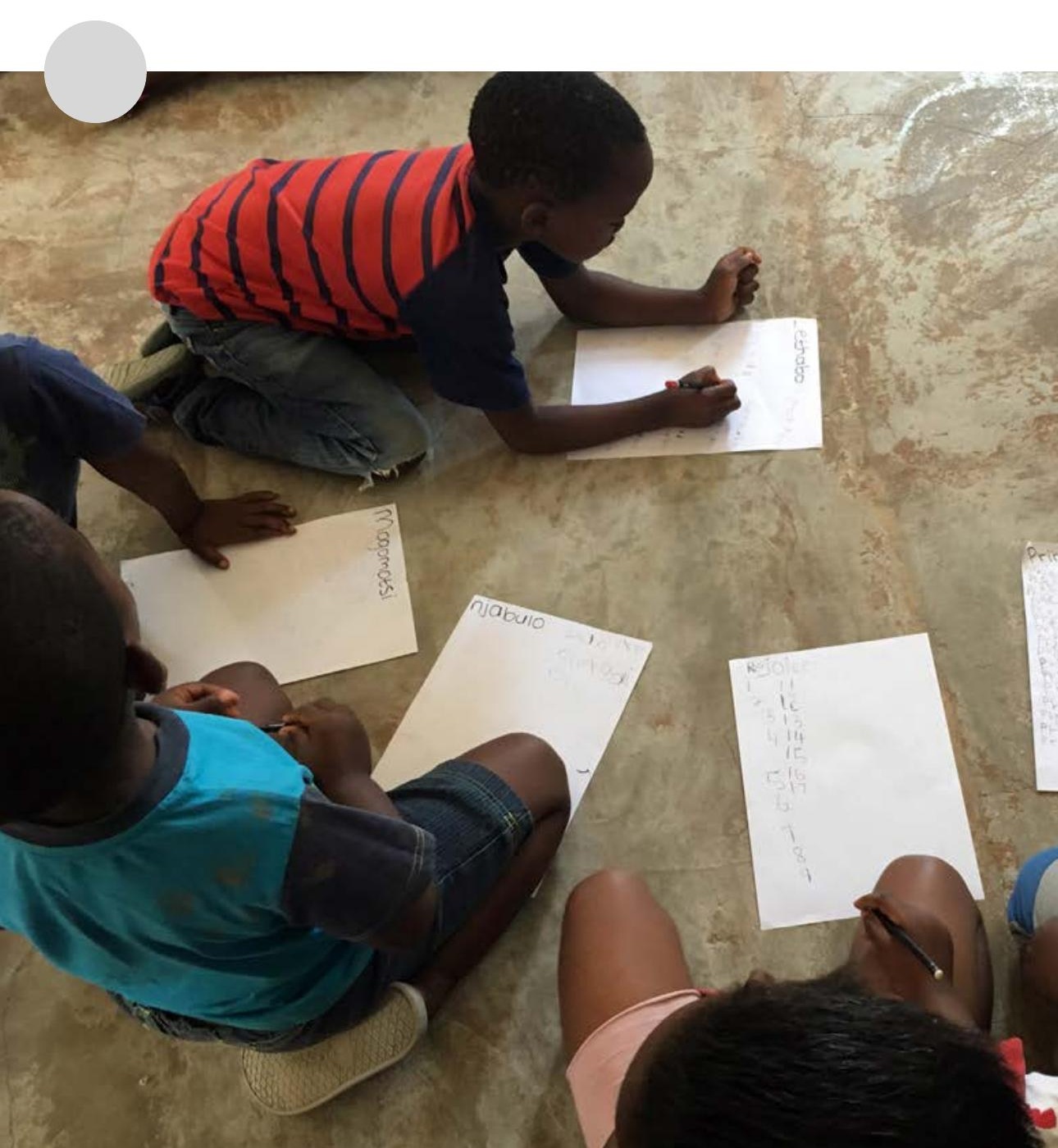

The teaching and learning of skills are also explicit in he curriculum. Life Skills (Foundation and Intermedate Phases) and Life Orientation (Senior and Grades 10-12) are specific subject areas within the curriculum with allocated time and suggested pedagogical practices. "The Life Skills subject is central to the holistic development of learning It is concerned with the social, personal, intellectual, emotional and physical growth of learnings, and with the way in which these are integrated" (p. 8, Department of Basic Education, 2011). Specifically, there are four study areas-beginning knowledge, personal and social well-being, creative arts, and physical education-through which learners are exposed to a broad range of knowledge, skills, and values, such as communication, creativity social and interpersonal skills, moral responsibilty self-confidence, self-disc d cultural values. Similarly, Life Orientation is intended to guide and equip learners for "meaningful and successful living in a rapidly changing and transforming society" (p. 4, Department of Education, 2002). It targets four learning outcomes: personal well-being, citizenship education, recreation and physical well-being, and career and career choices (Department of

The areas of the curriculum that the Department of Basic Education emphasizes as effective involve primarily literacy and numeracy skills. The country has done remarkably well in improving literacy and numeracy among all nine provinces of South Africa $a^{4}$. According to the department, in addition to the improvements in literacy and numeracy the Department of Basic Education has increased the percentage of children who access one year of preschool and has provided work materials to schools and improved infrastructure. However, the areas of education that can be improved upon are continuous professional development of teachers and environments that are more conducive to learning. From the perspective of the Department of Basic Education representatives, the effectiveness of the curriculum in equipping learners with the skills as stated in the goals is unclear. The other stakeholder groups generally recognize that skills are embedded in the curriculum and encourage learners to make new discoveries through group work and assignments however, they said that implementing the curriculum and targeting skills is difficult for various reasons, including lack of resources and funding, a curriculum driven by assessments with a major emphasis on content, and a lack of sufficient time or know-how to tea

With regards to policy priorities, there is a focus on early childhood development and the foundatio phase (Grades R-3), to provide a solid foundation for children to develop throughout their schooling careers. Priorities include a strong focus on literacy African languages, mathematics, science, and technology starting in the foundation phase, as these skills are believed to be foundational to all other skills. The Department of Basic Education is also working toward introducing an occupational stream in addition to the technical and vocational stream that is already in place.

Overall, based on the attitudes, perceptions, and responses from the Department of Basic Education, there is some indication of awareness of the challenges that different stakeholder groups are facing within the education system. The educational priorities and areas for improvement that the government put forth align with those cited by many, such as sufficien resources, a strong foundation in early childhood, and the importance of technical and vocational skills. Nevertheless, there seems to be a feeling that the input from teachers and school administators coudd be further strengthened in the making of polcy decibe further strongthened in the making of policy decithere, an understanding of differences perspectives among stakeholder groups concerning the effectiveness of the CAP curriculum may provide additional avenues for continued improvements in the quality of education for all students. 
between urban and rural employment and wages drives Kenya's relatively high rate of urbanization, but the industries in urban areas do not have the capacity to employ the influx of rural migrants, even when they are educated. This trend has affected the country for decades (e.g., NCEOP, 1976; MoEST, 2012).

\section{EDUCATIONAL BACKGROUND}

Kenya's first schools were introduced in the 1800 s by British missionaries who were primarily interested in proselytizing to the natives. The government organized formal schooling at the behest of European settlers in the decade before Imbova, and Gakunga, 2016). British administrators argued that different races required an education suited to their respective levels of development, and thus stratified the system according to skin color (Eshiwani, 1990). Although access to formal education slowly expanded for Africans throughout the first half of the 20th century, the colonial government ensured that curricula remained largely grounded in technical and vocational subjects so indigenous peoples could support higher offices (Mackatiani et al., 2016).

Segregation in education had a dual effect: It prevented Africans from attaining cognitive skills, but it also instilled in them an increasing desire to attain skills as they saw the benefits (higher status, higher pay better jobs) that education afforded their colonizers. Education, therefore, has been a and public since their independence. Howerer strong desire has asso ed to exceedingy high exstrong desire has also led to exceedingly high expectations for education-expectations that have no always been met (Oketch and Rolleston, 2007).

Upon independence, the new government planned to achieve universal primary education, expand secondary enrollments, and develop technical, vocational, and entrepreneurial education (Kenya, 1965). Education was to contribute to the chief goal of economic growth by quickly augmenting Kenya's supply of "skilled, trained and experienced manpower" (Kenya, 965). Education was also perceived as an important socialization tool for the new society to prevent its previous racial stratifications from carrying over into independence (Eshiwani, 1990). The twin goals of economic growth and social cohesion defined education for the first two decades of Kenya's independence.

School fees were eliminated in the 1970s (Nicolai, Prizzon et al., 2014) and school enrollments increased (World Bank online), but education quality did not improve. The high unemployment rate of graduates suggested a mismatch between what schools taught and what employers desired (ILO, 1972: NCEOP, 1976). The government responded to the o these criticisms in 1985 by launching a new 8-4-4 curriculum 5 to better connect education with the labor force (IBE 2010). The subjects did not change dramatically, but the Kenya National Examinations Council developed new, high stakes, end-of-cycle examinations for both primary and secondary school to encourage teachers to expand curriculum coverage (Eisemon, 1990).

However, in the midst of these reforms, the country's GDP stagnated, prompting the government to reintroduce school fees (broadly referred to as "cost-sharing") as part of the Structural Adjustment Program (SAP) proposed by the World Bank and International Monetary Fund (IMF) (Swamy 1994). As a result, enrollment numbers fell throughout the 1990 ( (Akala colition came to pow party because of campar coalition came to power partly because of campaign promises to abolish primary school fees again, a promise they made good upon during the next year, which registered tremendous success in opening up access to education for all. The 2007 elections saw another change in parliament associated with provision of free day secondary education (Hornsby 2013). A new constitution based upon social justice was ratified in 2010 (Watkins and Alemayehu, 2012). Just a few years prior, the government had also developed Kenya Vision 2030, which was built upon the progression of economic policies and frameworks the country had instituted since independence.

To align itself with the country's new vision and constitution, Kenya's Ministry of Education, Science, an Technology published a paper in 2012, Reforming Education and Training Sectors in Kenya, regarding the future of education reform in the country. It focused on non-routine tasks and complex problem solving as a result of the labor market evolution "from knowledge-reproduction to knowledge-production" (MoEST 2012). The paper also criticized the assessment system for education quality issues: Some subjects in the curriculum were not taught at all, primarily because they were not being assessed, and the subjects that were assessed had exams focused solely on regur(Wamahiu, 2015). Ultimately, the ministry called for the establishment of an organizaion (the Education Standards and Quality Assurance Council) to collaborate with the extant Kenya Institute of Curriculum Development (KICD) to define competencies in the country in preparation for future curriculum and assessment reform (MoEST, 2012).

\section{REFORM EFFORTS}

Kenya's education reform efforts have often been driven by responses to academic reports and public demand. The first policy in 1965 was taken from 1964 government-commissioned report and the of critical reports, two of which were government driven. As Kenya has become more democratic, education has played an important role in elections, with new coalitions attaining power in 2002 and 2008 partly because of promises to expand access to education and politicians since then advocating for increased quality of education. The reforms all ultimately point oward two goals: economic growh, at both the macro diverse citizenry.
Kenya is shifting its curriculum from content to competencies, "which will ensure that all learners acquire competencies and qualifications capable of promoting national values, inspiring individual innovation and lifeong learning" (MoEST, 2015). The curriculum reform is firmly planted in the realities of the 21st century: globalization, technological revolution, future unpredictability, and expanding needs of employers. The reform is also rooted in contemporary shifts in thinking around quality education, including the Sustainable Development Goals, the African Economic Outlook, and the OECD lifelong skills development strategy. Thus, the government acknowledges that "global trends in education and training are shifting" and is looking to align its education system with the latest education movements (MoEST, 2015)

\section{CURRENT EDUCATIONAL CONTEXT}

In Kenya, stakeholder groups' attitudes and perceptions on the skills that describe success, as well as those that are highly valued, are profoundly shas by the country's culture and context. All levels of the education system, which includes learners, parents, teachers, representatives of NGOs, and policymake and can influence the focus on education. The current examination of stakeholders' perspectives provides a range of views concerning the education landscape, building on a needs assessment survey for curriculum reform conducted by KICD in $2016^{6}$.

Stakeholder views were captured from September to November 2016. Participants were key stakeholders of education from the urban areas of Nairobi and the rural areas of Mai Mahiu and Kajiado counties (Table 2). Specific skills and other characteristics identified by the stakeholder groups as most valued are shown in Table 3. 
Stakeholders considered a range of skills, as well as personality traits and attributes, to be important. Overall, there was agreement on the need for 21 st century skills. For some, "21st century skills" is synonymous with information and communication technology (ICT) skills, with stakeholders discussing issues of using technology and embedding technology throughout the education system. The emphasis on ICT skills was partly because there are many challenges to learning. including language barriers, environmental conditions, inequality, and globalization. ICT skills were thought to bridge those "gaps" and bring together all learners through technology.

In addition, the stakeholders acknowledged the importance of holistic development, but the skills and traits that were valued tended to differ based on the developmental period of the learner. Specifically, in early opmental period of the learner. Specifically, in early
childhood, skills such as self-help, socialization, and childhood, skills such as self-help, socialization, and character were stressed. At the primary level, literacy and numeracy skills were often mentioned, along with nology and computer skills, critical thinking, creativity and problem solving Literacy and numeracy were seen as foundational and should be mastered be mastered before other skills are developed. At the secondary level, the skills learned in primary school were expected to be built upon. There was overall recognition by stakeholders that consideration of progression and development is important. Skills should be emphasized not only when learners get to the secondary level but much earlier, given the steep incline in development during early childhood.

Although there was acknowledgment that skills deveop and progress, based on the interviews with stakeholders, the breadth of goals differs depending on the developmental period, with broad goals identified in early childhood education, followed by narrow primary level goals, and then broad secondary level goals. stressed th importance of a strong foundation from an early age such as developing communication and social skills, and instilling confidence, faith, and trust. But, once children reach primary school, writing, comprehension, knowledge, and reading were most valued by parents. Primary teachers believed a broad range of skills is important: life, literacy, numeracy, communication, technology, and social skills. Nevertheless, the to be on passing exams, which are in the areas of literacy and numeracy. Teachers frequently mentioned exams as a mode of defining success. The strong focus on exams was specific to primary level teachers. Although exams were mentioned by other stakeholders, the conversation was not on getting students to pass but rather on the need to move beyond exams toward a focus on other important life goals. As such, concentrating only on what can be tested and pushing aside what cannot may contribute to the narrow primary level goals. Then, at the secondary level, life skills, self-dependency, and other skills "that are needed to prepare yourself for life need to be developed." Literacy and numeracy skills are critical at the primary level, to be able to get the basics, but once students reach secondary level, secondary teachers believed that "students should be ICT, teamwork, social skills, and innovativeness.

Some distinct patterns emerged among the stakeholder groups when identifying factors that characterize success. First, there was a marked difference between the stakeholder groups that work more closely with the learner (i.e, parents and teachers) and those more removed from the student (i.e., school administrators, NGO representatives, and government policymakers). Aside from literacy and numeracy skills, groups working closely with the learner named characteristic and traits as factors related to success, whereas the groups indirectly influencing the student were more likely to identify a combination of skills and traits. Parents and teachers valued traits and characteristics that are linked to future success beyond school, such as economic success, ability to meet basic needs, job readiness, a better standard of living than their parents, lack of the need to "hustle," and achievement of maximum potential. Although factors such as self-esteem, confidence, talent development, and goa achievement were mentioned, teachers seemed to put a priority on literacy skills and academic excellence (i.e., passing the exams). On the other hand, school izations, unions, associations, departments, and the ministry highly value collaboration, social skills, technology and computer skills, and critical thinking. They also highlighted the importance of passion and motivation for learning, survival and life skills, self-awareness, and being a productive member of society. In other words, what was most valued by the stakeholder groups shifts from a focus on personal attributes and skills related to the success of the individual child to characteristics linked to broader societal roles.

Many of the factors that characterize success in chidren were also mentioned when discussing teacher success. Characteristics and skills such as good values, social skills, a passion for teaching, life skills, collaboration, ICT skills, self-awareness, and creativity as well as having a positive impact on the learner, were identified by school administrators, teacher trainaks, and NGOs. Moreover, a successful wers por is eacher is student-centered, one who is collaborative and can have a holistic impact on the learner. Schoo administrators specified communication and character. Relatedly, stakeholders were aware that teachers need training in the skills they want to engender in learnrs to "inculcate the ideas and skil so that the tacher wil be able to cascade these skills the students" (representalive, Ministry of Education, Science, and Technology). Nevertheless, the pressures associated with examinations were evident, as school administrators specifically stated that successful teachers are those whose students pass their exams.
Across stakeholder groups, the following skills were dentified most often as important for school-age children: literacy and numeracy skills; ICT, technology, and computer skills; technical and vocational skills; life skills; social skills, critical thinking; creativity; and problem solving. Of note, literacy and communication skills were mentioned frequently, especially by teachers, wchool administrators, and teacher trainers. Howevrr, these were often seen as analogous to language skills, specifically knowing the mother tongue and overcoming language barriers when moving from one location to another. Furthermore, cultural and moral values, spirituality, love, respect, self-care, and confidence were mentioned by most of the stakeholders as important for learners.

When discussing how school-age children could develop a broad range of skills, parents and ECD teachers emphasized play as the primary method. Other stakeholder groups identified a variety of additional methods for teaching, such as demonstrations, "I do, we do, you do," experimentation, discussions, mitation, learner-centered approaches, and group work. While traditional, didactic methods of teaching were mentioned by some as barriers to cultivating skills, there was still a discussion of "giving students skills" and a mindset of teacher imparting learning to students, especially among parents and teachers. Although teachers recognized the importance of a range of skills, such as entrepreneurial, communication, social, and technical skills, they mentioned that much of what they do in the classroom is drill children with information, so that the che able to pass exams which and move to secondary. The skills that are not examnable are "shoved aside." Some teachers, however are aware that teacher-centered methods are not ideal:

If we continue teaching students like the way I was saying - banking system, a teacher tells students what to do and the students do that it uill not boost independency and our students will not have that 
sense of being independent and to have their own. It will be teacher said, parent said. With teacher centered, they will not have creativity, so I feel the teacher should come last. _-Secondary teachers, Mai Mahiu

Teachers of teachers viewed the teacher as a guide, allowing learners to be creative and make discoveries, although they acknowledged that pressure of completing the syllabus is an issue. Among policymakers generally, teachers were seen as mentors-people who look at learning in a holistic manner; facilitate learning of skills; help students build relationships; and impart wisdom. Policymakers frequently discussed the importance of inquiry-based learning, with students at the center of constructing their knowledge so that they better understand what they are being

taught. Furthermore, policymakers were more likely to mention the need to move to a child-centered pedagogy and often discussed the importance of teachers as "knowledge facilitators," rather than the ones "holding all of the knowledge," as well as developing children's skills rather than giving skills to them.

The learning environments that were recognized by stakeholder groups include school, home, community and other informal surroundings. Parents specifically identified a good learning environment to be one that is "friendly," both emotionally and physically. Moreover, they believed the main role that schools play in a child's growth is to provide knowledge, whereas parents need to focus on teaching morals and values at home. At the early childhood Iel, teachers held the common view that there is a need to create a conducive environment where children feel safe. Policymakers and assessors mentioned the home as importan for learning independence and morals, while citing school as the place to learn academic and technica

\section{CHALLENGES FACED BY EDUCATION}

\section{SYSTEM}

In addition to identifying the skills that are highly valued, the stakeholders voiced key challenges faced by the education system. Their general concerns and challenges are organized across five categories (Table 7)

Lack of resources and facilities and limited funding were mentioned by several stakeholder groups as major challenges for teaching and developing skills in children. The need for financial and techical reso in chis a theme that permeted al of the grouss, whoures is a theme that permeated all of the groups, with some mixed perceptions and attitudes. Specifically parents recognized the unequal distribution of resources and facilities between rural and urban areas, with rural schools lacking the resources, such as books, necessary for learning. Teachers also agreed, especially at the primary level, that there is a lack of ICT skills; teachers believe they are unate to povide the instruction without the resources. Without the "hands-on" learning, teachers said there is no point in teaching these skills because students will "not be able to try them out." On the other hand, teachers of teachers, who recognized the unequal distribution of resources, stated that schools do have resources but that whenever they visit the schools, these resources (i.e., technological devices) are not being used, and instead are "gathering dust," in part because teachers do not have adequate skills.

Another frequently mentioned challenge had to do with issues relating to teacher training, teacher preparation, and professional development (PD). There was serious concern about the lack of teacher skills and technical "know-how" to teach a broad range of skills. The Education Pillar, which is central to Vision 2030, requires Kenya to develop capacity to deliver world-class education. As a result, teacher capacity building was

\section{Table 7}

Challenges and concerns of the education system in Kenya by stakeholder group

\begin{tabular}{|c|c|c|c|c|c|c|c|c|}
\hline Categories & Parents & Teachers & $\begin{array}{c}\text { School } \\
\text { administrators }\end{array}$ & $\begin{array}{l}\text { Teachers of } \\
\text { teachersl } \\
\text { trainers }\end{array}$ & NGOS & $\begin{array}{l}\text { County } \\
\text { directors of } \\
\text { education }\end{array}$ & $\begin{array}{l}\text { Curriculum } \\
\text { developers }\end{array}$ & $\begin{array}{c}\text { Government } \\
\text { policy- } \\
\text { makers }\end{array}$ \\
\hline \multicolumn{9}{|c|}{ General concerns and challenges } \\
\hline Resource/funding & $\boldsymbol{\Delta}$ & $\Delta$ & & $\Delta$ & & & & \\
\hline Teacher training & $\boldsymbol{\Delta}$ & $\boldsymbol{\Delta}$ & $\boldsymbol{\Delta}$ & $\boldsymbol{\Delta}$ & $\boldsymbol{\Delta}$ & & $\boldsymbol{\Delta}$ & \\
\hline Involvement & $\boldsymbol{\Delta}$ & $\boldsymbol{\Delta}$ & $\boldsymbol{\Delta}$ & $\boldsymbol{\Delta}$ & & & & $\boldsymbol{\Delta}$ \\
\hline $\begin{array}{l}\text { Working conditions/ } \\
\text { poor infrastructure }\end{array}$ & $\boldsymbol{\Delta}$ & $\boldsymbol{\Delta}$ & $\boldsymbol{\Delta}$ & $\boldsymbol{\Delta}$ & $\boldsymbol{\Delta}$ & $\boldsymbol{\Delta}$ & & $\boldsymbol{\Delta}$ \\
\hline Broader context & & & & & & $\boldsymbol{\Delta}$ & & $\Delta$ \\
\hline
\end{tabular}

Current curriculum concerns and challenges

Teacher-centered
Exam-oriented
Too congested

New curriculum concerns and challenges

Awareness

$\Delta$

Involvement

Implementation mentioned frequently, primarily by stakeholders who are more removed from the child (e.g., policymakers and NGOs), and several trainings (Pre-Service Training [PRESET] and In-service Training [INSET]) have been implemented to help build the capacity of teachers, mainly in ICT skills. All teachers interviewed agreed that this training is important; however, representative from PRESET and INSET institutions mentioned a lack of execution from teachers based on the training. Regardless, PD was seen as inconsistent Some teachers have too many opportunities for PD and do not spend enough time in class, while others have little to no opportunities to attend PD. Who attends training seems to be arbitrary and at the discretion of the head teacher or administrator. Furthermore, the government and nongovernment agencies provide competing PD 
that is not aligned. In addition to the inconsistencies, many believed the training is inadequate, although some school administrators did mention that certain programs such as Tusome are very helpful in providing teachers with the skills they need.

Programs that are considered effective are those that bring together the practical and theoretical pieces of teaching, such as Strengthening Math and Science Education, whereas ineffective programs tend to be short, one-day courses. Teachers of teachers emphasized the need for practical work. They also proposed incorporating much of the training into university coursework rather than providing PD for teachers because, according to them, PD seems to be voluntary, and teachers sporadically choose whether to attend. All of these issues result in incapacity to teach students the skills they need to succeed in school and beyond. Relatedly, there seem to be discrepancies in teacher preparation at the university level (e.g., "teacher banks knowledge in student, and student stores that knowledge and copy-pastes it during exams") and how teachers, parents, and other stakeholders are saying teaching should be done. The most important methods of teaching seem to be learner-centered methods, discussions, demonstrations, and participatory learning - most of which move away from the idea of teachers as knowledge providers.

Alack of involvement in and commitment to children's education was often mentioned by all stakeholder

groups, with the exception of the country directors of education. Specifically, parents were aware that there are low levels of parental commitment in their children's development due to long hours of work necessary to meet family financial needs and the long hours that children spend in school, leading to a lack of

parent-child engagement in general. Parental illiteracy was also mentioned as an obstacle.

The need to increase teacher motivation was frequent Iy mentioned. Teachers, as well as other stakeholder groups (e.g. school administrators, policymakers, and NGOs), stated that teachers lack motivation because they are not as well-paid as their counterparts at the same level in the government and teaching is not recognized as a profession. Teachers also did not fee valued. They were "demoralized" by head teachers and by the government because they are not taken seriously. The majority of the suggestions from teachers, though, concerned increasing pay to motivate them more. In addition, policymakers and assessors menioned that most teachers lack passion as they have taken to teaching as the sole work option because of lack of employment in the country.

Related to motivation and commitment concerns, the most frequently mentioned challenge involved working conditions, including increased teacher-student ratio, low pay, lack of time, large workload, and poor infrastructure. Parents and school administrators were concerned about the increasing teacher-student ratio. Parents specifically worried that the increase affects the methods that a teacher can use for effective learning, as well as adding to teacher workload. Most parents and administrators agreed that a favorable clo shold range between 35 and 50 students per class, which would enable the teacher to have one-onone interactions with them; however, in most classes, the ratio is around 80 students per teacher. In terms of infrastructure, all stakeholder groups acknowledged that poor infrastructure is a barrier to quality education, particularly in rural areas. That means students across the country are not acquiring skills on an equal footing, translating into poor performance in marginalized or disadvantaged areas.

Concerns about the curriculum were voiced by parents and teachers of teachers or teacher traners. The three main concerns had to do with the curriculum being too teacher-centered, exam-oriented, and congested. Most parents in both urban and rural settings learners who are well-rounded or ready for the job market. Teachers were seen as no longer providing guidance to learners; but rather preparing them to perform well on exams. Examinations were frequently mentioned as constraining learning, although they were simultaneously seen as a measure of success or both the child and the teacher. There were indications from policymakers that with the new "competency-based" curriculum, formative assessment will be cyams. However, other stakeholder groups, such as parents and eachers, were unaware of these changes and wondered how skills would be assessed. In addition, the current curriculum was perceived to be "congested," making it difficult for teachers and students to focus deeply on subject areas, which affects learning. There is evidence that policymakers and curriculum deveis evers are aware of some of these chalenges opers are aware of some of these challenges, given to address concerns with the new curriculum.

21ST CENTURY SKILLS AND THE NEW CURRICULUM

In Kenya, the term "21st century skills" is commonly used by policymakers and other education stakeholders to refer to a broad set of knowledge, skills, work habits, and character traits that are believed by educators, school reformers, college professors, employers, and others to be critically important for success in today's world, particularly in collegiate programs and contemporary careers and workplaces. To thrive in the in more than just the foundational literacy. They will need as well to command extra competencies, such as working in teams, which implies a command of communication skills. They will need to be critical and innovative, as well as maneuver with agility in a digital knowledge economy. Beyond this, learners are expected to display character qualities, including leadership initiative, persistence, and ethical and other sensitivity in social contexts.
National curriculum reforms are typically launched in esponse to economic, political, and social pressures or exigencies. With 21 st century skills in mind, the curriculum reform is being undertaken to prepare Kenya to have the stock of human capital that will allow it to be fruitfully integrated into a competitive global economy. As a result of the revised curriculum, Kenyan tively in society, including at workplaces.

Curriculum is the backbone of education because it defines what is taught in every single level. Without curriculum, there is no education and that is the reason as to why we put a lot of emphasis. It is because you are touching many lives; you are shaping what actually the country expects because they are based on the aspiration of the country. Because when a country decides that this is what Kenyans want, you have to shape all the learners toward that direction. -representative, KICD

The Kenya Institute for Curriculum Development (KICD) is replacing the 8-4-4 curriculum with an age-appropriate 2-6-6-3 system. At the center of reforms is the need to impart the skills young people need to enhance their employability and economic productivity. The Taskforce on the Realignment of the Education Sector to the Constitution has proposed significant shifts in conceptualizing education quality, reevance, and outcomes. It seeks to enact the ambition of Vision 2030, which is to "have a globally competitive quality education, training, and research for Kenya's sustainable development." The curriculum reform proposals call for focus on broad areas of learning at all levels. For instance, even at lower primary, learners will be exposed to ethical preparation, acquire communication skills, and benefit from life skills. Accordingly, it is fitting to explore how policy can be geared to prepare Kenyan learners to acquire breadth of skills. 
A focus on 21st-century skills also means a need for changes in pedagogical approaches, such as emphasizing the role of the learner and de-emphasizing the role of the teacher as the primary source of information, moving to a competency-based approach, and shifting from mere content mastery toward deeper learning.

Existing policies require learners to be armed with the right skills to enable the country to realize its ambition. The current thinking requires learners at all levels to have and deploy multiple skills, competencies, and qualities. To this end, guidelines have been set out to fit the broad cc childhood level to senior secondary level.

KICD representatives anticipate facing certain challenges in formulation, implementation, and evaluation of the curriculum. The challenges range from microeconomic factors (within the organization and within the ministy) to macroeconomic factors, such as financing and preparing chldren with the sklls that meet the demands of the Kenyan market.

In addition to the challenges anticipated by KICD, other stakeholder groups mentioned three specific issues with the new curriculum (Table 5): lack of awareness of the new curriculum, lack of involvement of multiple key stakeholders in its development, and concerns lenges go hand in hand. Most of the teachers and some teachers of teachers were not aware of the

\section{CONCLUSION}

In Kenya, the attitudes and perceptions regarding the development of a broad range of skills reflect the overall country's priorities, including promoting susainable development and the importance of contributing to the society as a whole. The skills cited as critica inchol, life, a mited to life skills, literacy, numeracy, communication, problem solving, creativity, critical thinking, citizenship, science, entrepreneurialism, and ICT. In other words, broad range of skills is recognized as necessary for dapting to the changing needs and challenges of the

A successful person is regarded as one, irrespecve of surroundings and upbringing, who has been through an education system that has enabled him or her to excel not only in school, but also professionally and in society. Moreover, setting a strong foundation of education as early as possible for subsequent phases of learning is a critical component of the education system. The formative years in the learning cycle are seminal, strongly influencing skills and capabilities in later phases. The foundational skills include those in communication, manipulation, social interaction, and culture and arts. As children move from early childhood settings to primary and secondary school, priority learning areas change to reflect the goals of the different levels, from basic numeracy, literacy and life skills to a broader skills, and creativity. A fous on 21st century skills also means a need for changes in pedagogical approaches, such as emphasizing the role of the learner and de-emphasizing the role of the teacher as the primary source of information, moving to a competency-based approach, and shifting from mere content mastery toward deeper learning. Importance is placed on lifelong learning where value of education and success is based not solely on demonstrating evidence of learning, such as certification, but also on demonstrating the ability to learn new things and engage in novel, adaptive thinking throughout their lives. 
COUNTRY CONTEXT

One of the aspirations of education for a society is the development of its citizens in alignment with the vision cation. Enstined in the 1987 Philppine Constit cation. Enshy ined in the 1987 Ph ppine Constitution is the right of all citizens to quality education. The Philippines is experiencing a strong growth trajectory and along with China and Vietnam, is one of the fastest growing economies in Asia. The service and industry sectors in particular show excellent growth. The 2016 figures (Philippine Statistics Authority 2016a) capped a six-year growth period under President Benigno Aquino Ill's adminis both more oppotunites for skiled workers and both more opportunities for sklled workers and higher as preparation for engagement in the global community, the Department of Education has identified specific sets of skills in the following areas as being of most value to the country: 1) learning and innovation: 2) information, media, and technology; and 3) communication - all Iea are one component in the education reform being implemented in the Philippines.

\section{DEMOGRAPHIC AND SOCIO-} ECONOMIC BACKGROUND

The Philippines, located in Southeast Asia, is an archipelago comprised of 7.107 islands ( the Philippines, 2016). Based on the 2015 census, the country's population was 100,981,437 (Philippine Statistics Authority, 2016a). The Philippines remains one of the "younger" countries in Southeast Asia with 50.48 percent of the population age 24 or younger. The labor force has a 94.5 percent employment rate with many who are self-employed in small business. In the same survey, 44.7 percent work full time while 54.6 percentwork less than 40 hours a week. Three sectos percentwork less than 40 hours a week. Three sectors make up the formal labor force: agriculure 38.8 percent, industry 18.6 percent, and service 42.5 percent.
A large percentage of the unemployed is age 15-24. The Philippine economy generates about 8.5 percent of the country's GDP from its overseas Filipino workers (OFWs). In April to September 2015, the total number of OFWs was estimated at 2.5 million. Of these, 51.1 percent were female and 25.8 percent were in the 25 29 age group A good proportion of OFWs 39 percent) are skilled workers in the professionat, technica, centic clerical, and sevvice ind is the populace and is not seen as in the best long-term interests of the country (Philippine Statistics Authority, 2016b)

The Philippines development plan of 2011-16 outlined the country's need for growth (National Economic Development Authority, 2014), and an associated need to ensure that human capabilities are improved through education. With plans for further industrialization, the labor force needs to be equipped with appropriate skills. To address this, in May 2013, the Basic Education Act of 2013 was signed ir in the implem 2013 was sich $\mathrm{K} 1012$ Basic Educalon Program in the Philippines.

\section{EDUCATIONAL BACKGROUND}

The development of the Philippines' education system was shaped through its colonial past. During the Spanish occupation, Filipinos were taught by Spanish priests about the Catholic religion (Bauzon, 1981) and Spanish language and culture (Abinales and Amoroso, 2005) from the 1500 s onward. When the Americans defeated the Spanish in 1898, the Philippines' short-lived republic through the Malolos Constitution continued with a free education system, which is now mandatory for all. The Second World War led to the short occupation of the Philippines by the Japanese.

In 1947, the Philippines took full control of its government and education system. In 1973, President 
Ferdinand Marcos directed the education system to three fundamentals: 1) love of country; 2) duties of citizenship; and 3) moral character, self-discipline, and scientific, technological, and vocational efficiency. The post-martial law constitution of 1987 made elementary education compulsory for all Filipino children, and in 1988, Republic Act 6655 mandated free public secondary education. The Commission on Higher Education, in 1994, and then the Technical Education and Skills Development Authority, were established to supervise tertiary and technical and vocational programs.

Several iterations of the constitution and laws have emphasized qualities of morality, discipline, and citizenship

All schools shall aim to develop moral character personal discipline, civic conscience and vocational efficiency, and to them the duties of citizenship. -1935 Commonwealth Constitution

Character development, vocational efficiency, and citizenship training. - Department of Education and Culture, 1993

Education for character development; education for self discipline and self realization; and education for civic conscience and citizenship. —Manuel, 1996

Filipino develops into an individual who respects human rights guided by spiritual and moral values and can think critically and creatively and who can exercise his or her rights and duties as a citizen. whose mind is informed by science and reason, and whose mind is formed by knowledge of Philippine history and cultural heritage.

-Fidel Ramos administration, n.d.

When President Joseph Estrada assumed office in 1998 the educational philosophy was to produce

Filipinos who could be used as manpower for different industries and thereby reduce poverty Under Gloria Macapagal-Arroyo (2001-10), the Basic Education Curriculum (BEC) was enhanced by prioritizing the upgrading of teaching of mathematics and science in the hopes of producing knowledgeable workers Gloria Macapagal-Arroyo Initiatives, n.d.)

\section{K TO 12 EDUCATION REFORM}

Under the Corazon Aquino administration (2010-16), the Enhanced Basic Education Act of 2013 was implemented. This 13 -year $\mathrm{K}$ to 12 Program is a response to the growing need to be globally competitive through provision of basic education. The Philippines was the final country in Asia to implement a 12 year be education progam. The program is intended to ensure accreditation of student qualifications internationally. A child can now enter school at 5 years old into what is known as the "kindergarten" year, prior to Grade 1 entry. Another landmark component of $\mathrm{K}$ to 12 is that it mandates the mother tongue as the medium of instruction for the first four years of schooling. The objective is to optimize students' learning experiences hrough being taught in their mother tongue. A third notable feature of the program is the "spiral progression" of learning in which basic concepts are built on across years with layers of increasing complexity. This is particularly the case for mathematics and science. In the past, science, for example, was taught one track at a time: biology in one year, followed by chemistry in another and so on, through the secondary years. Through the spiral progression, each of these revisited each year. Added to these structural changes is increased focus on understanding and application of student learning. To give shape to this emphasis on the need to build understanding is the adoption of 21 st century skills. Accordingly, under $\mathrm{K}$ to 12 , the curriculum mandates that key skills within three major groups be taught: learning and innovation, communicalion, and information media and technology in turn, cilon, andinformation media and technology In turn, career skills.

Not only skills were valued by the stakeholder groups, but also attributes that are associated with nationalism, citizenship, and individual integrity.

The $\mathrm{K}$ to 12 Program is a major reform of the education system, in terms not only of curricular, pedagogical, and assessment changes, but importantly to the addition of kindergarten and Grade 11-12 years. The addition of the two latter years poses huge challenges, not only in having to design a new curriculum, but in providing teacher training and thinking through the implications for the higher education sector. Beyond iscues of expertise are logistic challenges of $p$ issues of expertise are logistic challenges of providclasses in schools.

\section{CURRENT EDUCATIONAL CONTEXT}

There is dissension in the Philippines about the advisability of the $\mathrm{K}$ to 12 Program. The issues fall mainly into two categories. One centers on economic and workforce implications, and the other on readiness an competence issues in the education system itself. The current scan of attitudes and perceptions associated with change in the education landscape is timely given he major transition

Stakeholder views were captured from August to December 2016. Participants were key stakeholder of education: parents whose children were enrolled in public schools, teachers in public schools, administrators and district superintendents involved in the education system, and representatives of the higher education sector.

Specific skills and other characteristics identified by the stakeholder groups as most valued are shown in
Table 3. It shows a high degree of consistency overal across the stakeholder groups and, to a slightly lesser degree, between the Philippines and other countries. Notwithstanding, there were some differences across the Philippine stakeholder groups.

It is noteworthy that it was not only skills that were valued by the stakeholder groups, but also attributes that are associated with nationalism, citizenship, and individual integrity. Stakeholders did not discuss the degree to which these can be addressed by the formal education system.

A number of themes emerged from the data. First, it is noticeable that parents most valued the capacity to be independent, provide for self and family and be stable and honorable as being most strongly associated

with being a successful person. Teacher groups also highlighted independence and provision for others as highly valued. The stakeholder groups that are more removed from the individual child tended to value somewhat different characteristics, moving to focus on cognitive and social skills, goal setting, and societal roles.

In terms of skills valued, it was literacy, numeracy, and interpersonal skills that dominated the views of those closest to the child, including parents, the ECD community, and teachers. Parents, however, also valued daily skills for living, while teachers also identified cogdally skils for ling, whle teachs also identified cognitive and self-regulation style skills. Again, those more removed from the child at system level tended to iden-
tify higher level cognitive and social skills, such as cre- 
ativity and flexibility, collaboration, self-awareness, and independence. Teachers emphasized the functional aspects of sets of skills leading to more sophisticated capacities, with analytic skills, for example, providing the facility to develop observational, scientific, and problem solving skills. Likewise, social skills such as communication were valued because they enable the demonstration of other skills, rather than only in their own right. Finally, by senior high school level, the child was expected to be able to apply all the learning and know what skills are necessary to bring to a particular task or situation.

Concepts such as independence, responsibility, and happiness may mean different things to different people. In the Philippines, there appear to be strong links among the concepts, with stability of work and providing for one's family also standing for independence, responsibility, and happiness. These concep are societal insofar as parents see them as instilled children from a young age. None of these concepts are necessarily associated with completion of basic education or earning large sums of money. Working with honor is premium.

Parents appeared to value literacy, language, and communication skills, with little distinction between them. Communication was valued as a daily living skill, which raises issues around the language medium itself. Mastering both Filipino and English was seen by parents as essential since these are the officia languages of the country and used extensively in business. The introduction of teaching through the mother tongue as a language of instruction for the firs four years of school has raised some concerns among some parents about impact on children's mastery of the official languages. At the same time, members of the ECD community and the education sector more widely saw the mother tongue as providing a more natural entry to formal learning for the young child. A connected major change for young children in the education system is the introduction of the kindergarten year as compulsory. This has reportedly led to some parents no longer sending their children to preschool, because they see the years of the education system as already protracted. That kindergarten is now mandated is interpreted by many that it is a formal rather than a preparatory year, as in the past. This raises issues around the ways that children learn. Parents saw ctivities, with observation and imitation characterizing the former, and instruction characterizing the latter With identification of kindergarten as a formal year of schooling, some parents feared that informal learning for example through experimenting and practicing, may be de-prioritized. Another new development is the internet, with parents identifying social media as providing information sharing and learning opportunities

Policymakers, the stakeholder group most removed from the child, identified four skills associated with success: critical thinking skills, creative skills, social skills, and discipline. Students can be considered critical thinkers if they ask questions, participate in discussions, and apply and test what they learn. With this, a holistic approach is developed that will help students excel in any field. Similarly, creativity is valued in providing the capacity to "think outside the box" to support advanced academic, practical, and research skills for the Philippine workforce. Discipline is regarded as a critical skill in the work environment and in the household. Being of service and being happy are regarded as markers of success.

\section{CHALLENGES TO IMPLEMENTATION}

\section{OF THE K TO 12 REFORM}

Moving away from the skills and qualities identified as important by stakeholders, a clear communication from system-level participants consisted of the many challenges faced by the education system (Table 8 ). One of these was the lack of support for the reform from many parents and their lack of active involvement in their children's education. At the societal leve

\section{Table 8}

Challenges and concerns identified by Philippines stakeholder groups

\begin{tabular}{|c|c|c|c|c|c|c|}
\hline Categories & Teachers & $\begin{array}{c}\text { School } \\
\text { administrators }\end{array}$ & $\begin{array}{l}\text { Teacher trainer; } \\
\text { Higher Education } \\
\text { Institution }\end{array}$ & $\begin{array}{l}\text { Commission } \\
\text { on Higher } \\
\text { Education }\end{array}$ & $\begin{array}{c}\text { Department of } \\
\text { Education Bureau of } \\
\text { Curriculum Standards }\end{array}$ & $\begin{array}{l}\text { Government } \\
\text { policymakers }\end{array}$ \\
\hline $\begin{array}{l}\text { Teacher training/lack } \\
\text { of teacher skills }\end{array}$ & & 0 & 0 & & 0 & \\
\hline Parental involvement & & 0 & & & & \\
\hline $\begin{array}{l}\text { Lack of facililites/ } \\
\text { resources }\end{array}$ & & ○ & ○ & & 0 & ○ \\
\hline $\begin{array}{l}\text { Poor working } \\
\text { conditions for } \\
\text { teachers }\end{array}$ & & 0 & & & & 0 \\
\hline $\begin{array}{l}\text { Adjusting to new } \\
\text { curriculum }\end{array}$ & 0 & & & & & \\
\hline $\begin{array}{l}\text { Adapting to } \\
\text { technology }\end{array}$ & 0 & & 0 & & & \\
\hline $\begin{array}{l}\text { Assessment } \\
\text { strategies }\end{array}$ & 0 & & & & & 0 \\
\hline School environment & & 0 & & & & \\
\hline Broader context & & & & 0 & & \\
\hline
\end{tabular}

Note: Parents, District Superintendents, and Department of Education, did not specifically discuss challenges this may relate to the economic issues faced by the community, where the need for children to contribute to their family's economic survival may also contribute to absenteeism from school and lack of enthusiasm for the additional years of education that are a signature feature in the K to 12 reform. In the context of the large OFW workforce, some families may also prefer to send their sons and daughters abroad to earn money rather years. However, years. However, the is also increasing acceptance of K to 12, since familes see that their children do not have the necessary educational background to enter the overseas job market.
Another challenge concerns the readiness of the teaching force. An important aspect of the $\mathrm{K}$ to 12 education reform is a focus on students' capacity to practices, for assessment, and for how skills that are valued are taught. The Philippines' identification of the "holistically developed Filipino" refers to the spiritual, mental, physical, and emotional aspects of the person. It highlights the importance of development across It highlights the importance of development across learning and innovation, communication, and information media and technology — with these three leading to positive life and career outcomes. Accordingly, understand what is taught and to be able to apply their learning. This focus has implications for pedagogical 
The challenges are a natural consequence of the nature of the reform itself. To facilitate student understanding of concepts, teachers themselves need to have deep understanding and know what pedagogical strategies can best be brought to bear with students at different stages of learning. This is quite a different challenge from that of delivering content and operating in a teacher-centered classroom It is no longer sufficient to provide knowledge_-it is necessary to model how to store, manipulate, retrieve, and analyze information.
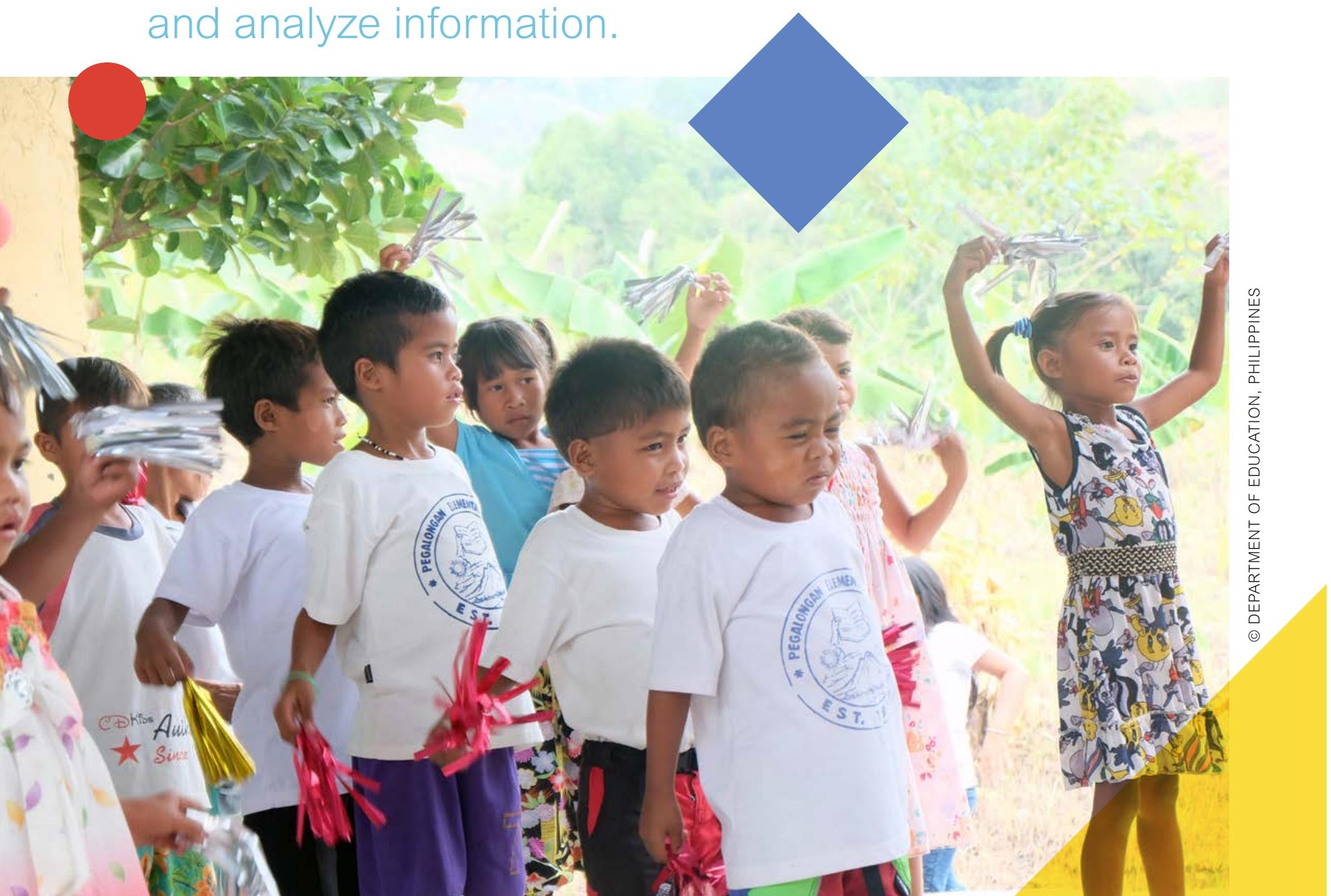

these sets of skills are to be taught and developed through curricular studies. At the most explicit level, speaking, listening, and writing skills will be found embedded through language-based studies such as English, Filipino, and social studies; analytic and critical thinking skills will be found explicitly in science, math, and computing; and so on. The new curriculum has restructured how lessons and compet are designed seen by teac because of the spira approach to teaching science. because of the spiral approach to teaching science. Under the reform, teachers who previously specialize in a particular track, such as biology, taught only that track. Now all science teachers in the junior secondary years are expected to teach across the full science curriculum. Teachers report challenges in adjusting to the new curriculum and to the technology that is around them. For example, while critical thinking skills are prioritized, teachers who are unfamiliar with online technologies now need to familiarize students with how to analyze resources critically, but are unsure of their own competencies.

Similarly, where student understanding of information is valued, as opposed to rote memorization, assessment becomes more complicated. The Department of Education (DepEd) has established a new assessmen framework for the country and prioritized formative assessment. However, educating the current teaching force to adapt its teaching and assessment strategies to these new goals remains a challenge. DepEd has adopted mechanisms such as learning action cels evelopment opportunities to teaching staff as part of weekly life. LACs are much like what are known as professional learning teams in many countries. LACs are essentially meetings of teachers where they focus on learning and teaching issues, and benefit from in-service style professional learning, as opposed to the administrative and management issues that dominate many schoolbased meetings.
The challenges are a natural consequence of the nature of the reform itself. To facilitate student understanding of concepts, teachers themselves need to have deep understanding and know what pedagogical strategies can best be brought to bear with students at different stages of learning. This is quite a different challenge from that of delivering content and operating in a teacher-centered classroom. It is no longer suficient to provide knowledge in is necessary to sufficient to provide know model how to store, manipulate, retrieve, and analyze information. The challenges can be met only through additional teacher training and through deeper understanding of the nature of the skills that DepEd believes are important for students to acquire.

These challenges are mirrored at the teacher trainer and higher education levels. Although teacher trainers report using technology when they teach, the actual infrastructure available for such integration is inadequate in tertiary and basic education. Teacher trainers themselves come mainly from a generation where there has been little experience of current technologies and where pedagogical strategies have tended to focus on transmission of knowledge rather than develop on tant of skils. Notwithstanding, the educetionat philosophy identifed by these groups is very much aligned with the concept of starting points for teaching from what students know, and then moving forward to introduce increasingly complex concepts and processes. Teacher trainers reported seeing the new curriculum as responsive to the globally changing world, in particular in providing Filipinos with an education that will be globally competitive.

Although a major goal of the $\mathrm{K}$ to 12 reform is to produce graduates who will be recognized for their educational qualifications worldwide, contribute to the Philippines' economic growth, and be educated in specialist areas, there is recognition that 21st century skills must be taught from elementary level onward for the achieved. Thew-through effect, no only for the need for more highly qualified entrants in 
the tertiary sector, but also to the different skills they will have, has implications for how the sector can lead and respond to the changes.

The $\mathrm{K}$ to 12 reform has repercussions for the tertiary sector workforce, and some of these have led to

public negativity about the changes. Not only does the

tertiary sector need to upgrade its own qualifications, since the majority of its incumbents themselves have come through a 10-year basic education system, bu there are also logistical challenges. In the short term these have concerned the fact that as the first years of Grades 11 and 12 implementation occur, the tertiary sector will not receive new entrants to the system. The Grade 10 exit students, rather than going to university, will remain in school to study Grade 11 and hopefully Grade $12^{7}$. Two employment issues emanate from th First is the need for teachers to teach at Grades 11 and 12; second is the lack of employment opportunity for the current tertiary sector employees for the gap years. Also to be considered is that when these new $\mathrm{K}$ to 12 graduates enter tertiary education, they will Ke two years more ed than their predecessors with consequent transition issues and demand for higher level expertise on the part of the academics in the higher education secto

These employment issues are exacerbated by the appropriateness of skills of personnel who might be able to contribute. The Commission for Higher Education is continuously training its instructors and widening its pool of professors and instructors who are experienced in the field that they are teaching. However, among some, there is a perception that the $\mathrm{K}$ to 12 reform is an imposition. There are issues not only of human readiness but also of teaching resources. This matter of teaching resources perme tes many levels of the system but is problemalic in the senior secondary ary education sector. This is due to the recency of development of the new senior years curriculum, as we as to issues of profitability for the publishing sector. For example, there has been a shortage of learning materials due to disinterest from publishers in printing relatively small orders for some senior high school subjects. In-house development of learning materials is one way of addressing the problem, given that the process/development of these learning materials is reportedly "very tedious" and "time consuming."

\section{SYSTEM LEVEL}

The educational shift aspires to a system in which students are no longer merely taught to memorize and pass examinations, but rather how to live and to stand on their own. Through this system, government looks at every subject to identify whether it supports tudents to learn based on their needs. The shif is toward a holstic stye that pronizes how to thith. This towerd a holstic style that prionlizes how to think. This shift has consequences for curriculum materials, for pedagogical strategies, and for how assessment tools are developed, not only for within classroom use, but for national assessment purposes.

The government, therefore, has both logistic and substantive issues to confront: the development of eaching resources, teacher salary and recognition, and development of a holistic approach in education. Government is working toward increasing salary levels especially for entry-level public school teachers, in part to discourage them from going abroad to work.

The government is also taking steps to improve retraining of teachers to help them adapt to the new system. For the substantive issues, rewriting of the curriculum was the first step. Revision of the Philippines assessment framework was also started in 2015, with consequent cancellation of some of the large-scale nationa assessment events, and a growing enthusiasm for formative assessment approaches to pedagogy in the classroom.

The $\mathrm{K}$ to 12 curriculum is seen by some as overly ambitious. Although Grades 11 and 12 are designed to provide students with a choice of specialization-academic, technical, arts, or sports-in fact, many public schools can offer only technical-vocational (tech-voc) courses because they lack facilities to cater for courses including science and technology, humanities, or math. The tech-voc courses also prepare students to work abroad, which links to the reliance of the economy on remittances of OFWs. Most agree that the goal is for education to strengthen a self-sufficient economy. During the lead-up to the reform, there was some controversy about Many called for pilot approaches to the reform, but the

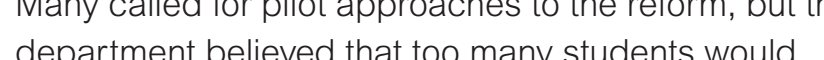
miss the opporunty for to many students would miss the opportunity for a full education by delaying the implementation.

NATIONAL VISION AND THE EDUCATION AGENDA OF THE PHILIPPINES

The national vision is aligned with the concept of a sustainable development for all. Under past President Aquino, a 10-point education agenda was agreed:

1. Expand the basic education in the Philippines from a 10-year cycle to a globally comparable 12 years before the 2016 administration.

2. All public school children (and public schools) will have a full year of preschool as their introduction to formal schooling by 2016.

3. Full basic education for all Muslim Filipino children anywhere in the country.

4. Reintroduce technical-vocational education in public high schools to better link schooling to local needs and employment.

5. Every child must be a reader by Grade 1 by 2022.

6. Rebuild science and math infrastructure in schools to produce more scientists, engineers, technicians, echnologists, and teachers in universities so that the Philippines can be globally competitive in industry and manufacturing.

7. Expand government assistance to students and teachers in private education program.

8. Trilingual as a country: learn English well and connect to the world, learn Filipino well and connect to the country, retain dialect and connect to heritage.

\section{Better textbooks.}

10. Install schools where there are no public and private schools, in agreement with local government units to realize genuine education for all.

The $\mathrm{K}$ to 12 reform was designed to address this ggenda. The effectiveness of the new curriculum will not be known for some years. The first graduates from $\mathrm{K}$ to 12 will be in 2024. Assessments to be adminisered in the interim, such as in Grade 3, may provide information about the effectiveness of mother tonguebased multilingual education. Similarly, students progressing out of elementary school will complete national assessments that are being developed to include assessment of 21 st century skills. ${ }^{8}$. At the same time, approaches to classroom assessments are including formative strategies to help provide interim indications of the effectiveness of $\mathrm{K}$ to 12 .

SUMMARY OF STAKEHOLDER VIEWS Across focus groups and interviews, a holistic view of the individual that covers personality, mental capacity, and happiness tended to prevail. When describing success, while key skills were identified, so were personality traits. During the discussions, stakeholders identified perseverance, commitment, discipline, and dedication as contributors to success. In essence, success was seen as involving some form of hardship or sacrifice. All groups concurred in believing that skills require proper training and development, and 
that formal education is essential for this. However formal education alone was not regarded as a predictor of success.

Success was associated with being able to provide for one's needs, contribute to society, and doing what is "expected." At minimum, this implies fulfilling a family role. To do this, the individual must be competer have the required knowledge. Success also appears to be about independence, being able to stand on one's own without depending on others. Notwithstan ing this emphasis on independence, success also means being empathic and sharing knowledge for the community benefit. This calls upon creativity and innovation to contribute to progress and better life.

In terms of skills, communication skills appeared most valued. This feeds into human interaction and cooperation. In terms of learning, communication skills enable teachers to assess students and to transfer learning and skills to students. Literacy and numeracy skills are seen as preconditions for success, in that they facilitate further learning and provide access to higher order skills, such as critical thinking and problem solving. "You do not take things as they are, you look for ways to make things better, you question, you look for ways to make things better, you question, and you become resourceful because of it," said on participant.

In terms of pedagogy, play was seen as an effective strategy for younger children, while for older students, a variety of teaching methods was considered effecconsidered effective. Lecturing and discussion were the most commo strategies, accompanied by collaboration on group work and use of multimedia. There was an awareness that learning takes place across both formal and informal environments- the home being the primary example of the latter. The internet was identified as new forum for learning, primarily through access to information rather than for its social skills benefits.

\section{CONCLUSION}

For the Philippines, 21st century skills are core to the $\mathrm{K}$ to 12 Curriculum since implementation of the reform in 2013. However, as with any change, the $K$ to 12 reform has not readily been accepted by all. Some parents are unhappy with the larger number of schoo years that it prescribes. Another concern is how wellequipped teachers are to carry out the new curriculum. As the main goal of the curriculum is to teach the skills to students, the old-school style of teaching needs to change, while instructional aids also need reviewing. Associated with the need to change pedagogical strategies is the need for teachers to learn how to use technologies how to use technologies to a grear extent in their professional lives. Readiness of the higher education sector for the new curriculum is a related issue. How trainers of teachers are to develop the 21st century skills they need to educate a new generation is unclear. In addition, readiness of schools for accessing and integrating facilities required for teaching 21st century skills is a concern.

Nevertheless, the new curriculum has gone through consultation process, and the skills are embedded in the curriculum. It is early in the change process, and arge scale assessment data from students graduating from $\mathrm{K}$ to 12 are not yet available. However, the Department of Education has adopted a research agenda through which educators are encouraged to participate in ongoing research efforts. In addition, monitoring of progress as the reform unfolds ${ }^{8}$ is underway in collaboration with the department.

The impact of the Philippines education reform is huge. This is due not only to a philosophical change in how education should prepare its youth for society, but also to the immense logistic challenges that it places on the country. Preparation for a 21st century world has imposed difficulties for which some believe the country is ill-prepared. Others acknowledge the difficulties but do not believe that these are so great as to justify delay that would disenfranchise current students. Preparation of its youth for a 21st century world has propelled the country into valuing children's understanding and application of knowledge and recognizing that more years of education are necessary or the development of the expertise that the country needs.

Students are honed to become critical thinkers, problem solvers, good communicators, good collaborators, and information and communication technology literate, globally competitive and financially literate. These 21st century skills are the aim of the $K$ to 12 program. - Director of one of the bureaus of DepEd
Notwithstanding this explicit change in direction for the education system, its goals remain strongly aligned with the country's history of aspirations for its people particularly in terms of its citizenship principles. 


\section{Themes}

\section{across the}

\section{four countries}

This section highlights trends that appeared across countries and stakeholder groups. As indicated in the country-specific reporting, study participants from the four countries were members of six stakeholder groups: parents, teachers, school administrators, teacher trainers/lecturers, and nongovernment and government personnel. Nongovenment personnel included key opinion leaders and representec associations, and ot associations, and other organizations. Government personnel included policymakers, country directors, curriculum developers, and other representatives of ministries of education, and departments of higher and basic education. Although the same groups were targeted for their views across the four counties, they cannot be seen as equivalent. Particurarly among cannot ser virtue of diferent govern, representatives varied by virteof aiferent governing structures and roles and espon availability issues

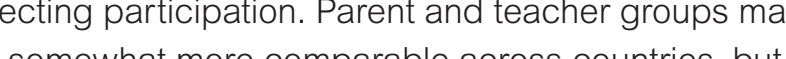

vary socio-economically and by urban or rural locaThe countries, actors that characterize success, as well as valued skills, were categorized into four groups: 21st century skills, academic skills, character traits, and workforce and society characteristics. Factors and sklls that ty che cluded in this analysis because the intent is to paint a broad picture.

Overall, when describing factors that characterize success and identifying highly valued skills, three he stakeholder groups that work closely with the chid and the groups that are more removed from the child (Figure 3); 2) ce are mentioned by all countries; 3 ) there are also clear differences between countries in the factors and skills that are highly valued and emphasized.

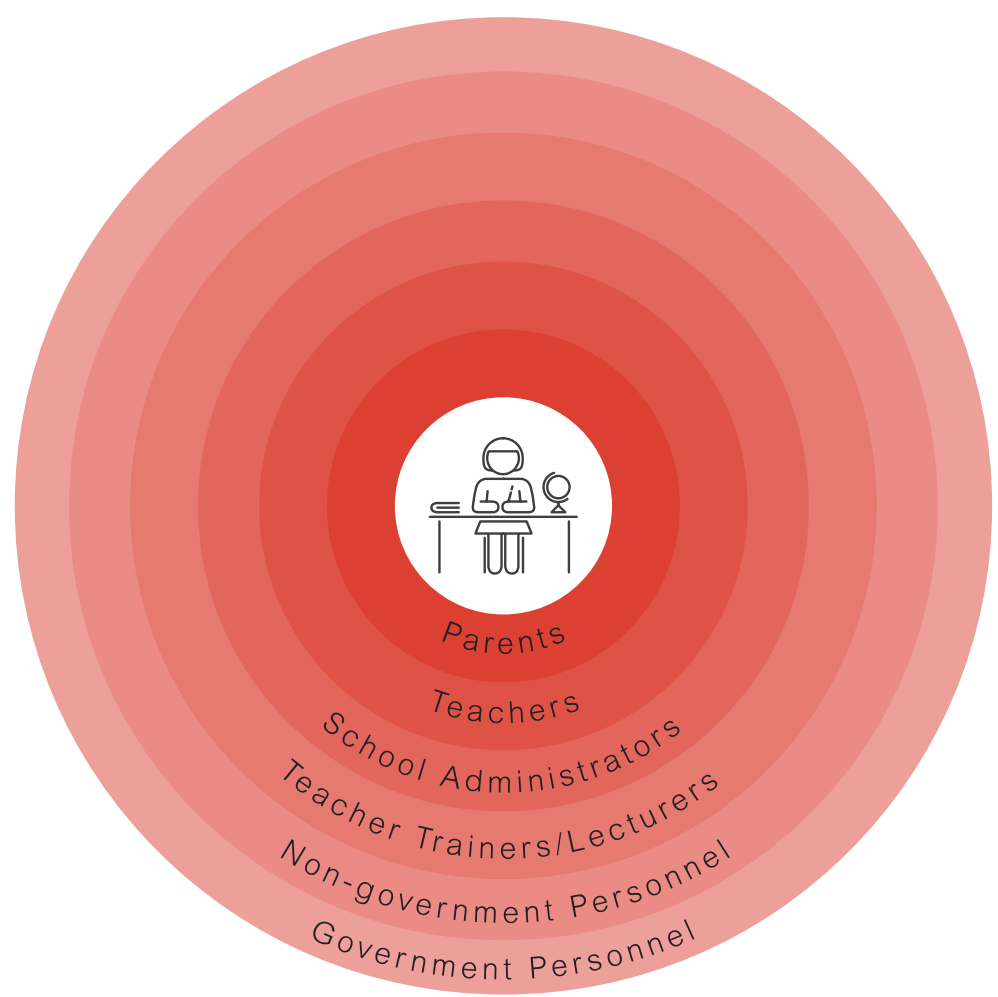

\section{"SUCCESS CHARACTERISTICS"}

The question of what characterizes successful people was ask (a) responses ranged across 21 st century and academic skills, traits, and characteristics associated with workforce and society (Table 3).

Across the four countries, 14 main 21st century skills were identified as important for students to acquire. The skills most frequenty mentioned were commuThe skils most frequenty mentoned were communication, social and interpersonal skills as a generic skillset, and critical and analytical thinking; those leas cited were collaboration and teamwork. Although it is clear that the latter two require social skills, the respondents may have been more attuned to the work aspects of these skills than to the social aspects.
Differences emerged across stakeholder groups. Specifically, there were distinct patterns between stakeholder groups that work closely with the child, such as parents and teachers, and those that are more removed from the child, such as teacher trainers and nongovernment and government personnel. This general pattern was evident across all four countries.

Twenty-first-century skills, for the most part, were not associated with how parents defined success. Parents,

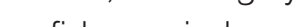
confidence, independence, responsibility, being productive members of society, happiness, and appropriate morals and values. In fact, parents did not mention 21 st century skills when discussing factors that characterize success. The exception was Mexico, where parents highlighted the importance of self-awareness 
and social skills, which was in line with the fact that socio-emotional skills are an important component of the country's educational agenda. Teachers also identified similar characteristics, such as confidence and independence. In contrast, 21st century skills were featured as contributors to success for the more removed stakeholder groups. Across all four countries, nongovernment and government personnel emphasized communication, social skills, critical thinking. and technology and computer skills.

Although these patterns apply to all four countries, the differences among stakeholder groups were especially noticeable in Kenya, where parents and teachers did not identify 21 st century skills at all. Instead, the focus seemed to be primarily on academic skills, character traits, and workforce and society characteristics, such as job readiness skills, morals and values, ability to provide basic needs, and independence-all factors linked to the individual child's future success. On the other hand, the more removed stakeholder groups identified a broader range of skills to include 21st century skills, character traits, and workforce and society characteristics, such as communication, critica thinking, proble trats reted to the goals of the country. It is hypothesized that this phenomenon is a natural alignment of the context and goals of the different learning environments. Although parents value academic skills, they more frequently see other aspects of their child, such as personality and social behaviors. Similarly those in formal education roles are acculturated to the goals of those roles and the services that the education systems value.

Notably, except in Kenya and South Africa where variously the parent and teacher groups nominated literacy and numeracy skills, very few stakeholder groups across all four countries mentioned academicrelated skills when describing success. However, al stakeholders across all countries acknowledged the importance of workforce and society characteristics.

\section{"VALUED SKILLS"}

Interestingly, the patterns were different concerning the skills that were highly valued for learners. Unlike for factors related to success, a broad range of 21st century skills, such as collaboration, communication, and computer skills, and listening skills, were mentioned most frequently by those closes to the child (parents and teachers). Specifically, the skills that parents across the four countries nominated most frequently were communication and social skills, along with the academic skills of literacy and numeracy. Technical and vocational skills were also identified as important across sou ippines. From the coherence of these data, it could be concluded that parents still see the primary function of education as providing academic skills.

Teachers across all four countries most frequently identified critical and analytical thinking as valued, with various social skills and technology-related skills atso identified Language/theracy skills are identified ubiquitously, followed closely by numeracy but less so for science. In terms of workforce skills, entrepreneurship was identfied by teachers in all countries apart from the Philippines. Given the high percentage of small-business owners in the Philippines, this is of interest. Perhaps it echoes the hypothesis, made on the basis of the paras primaily providing academic sklls training.

On the other hand, for government personnel across all countries, the skills that were valued did not fall only into the category of 21 st century skills but were distributed across 21 st century and academic skills, character traits, and workforce and society characteristics.

The other stakeholder groups, namely school administrators and teacher trainers/lecturers, and to a certain extent nongovernment personnel, were less likely to name a wide range of skills and instead tended to place greater emphasis on a few critical skills and raits. For instance, school administrators and teacher trainers, depending on the country, valued critical and analytical thinking, self-regulation, academic skills, and values. To note, school administrators from Kenya did part, a function of the data collection process (i.e., the subject of highly valued skills may not have come up during the interviews). Discussions were primarily centered on the skills that are highly valued for teachers, teacher training, and their roles as administrators, rather than on skills for school-age children. Overall, workforce and society characteristics seemed to be associated mainly with success, whereas 21st century skills and academic skils were highly valued. Hontury skills and academic skils were highly valued. However, for parents and teachers, the focus shifted betwe
success and skills from an emphasis on character traits and workforce and society characteristics to an emphasis on 21st century and academic skills, indicating that for these two groups there is a distinction between success and highly valued skills.

Teacher trainers and representatives from higher education institutions were more likely to talk about skills that teachers need, as opposed to those that are valued for children. Valued skills for teachers included communication, critical thinking, self-awareness, socia and interpersonal skills, positive influence and role model, and passion. This points to the understanding that changing goals for students means there must trainers.

\section{DIFFERENCES AND SIMILARITIES} ACROSS COUNTRIES

"Success Characteristics"

In addition to stakeholder differences and similarities, patterns emerged on the factors that characterize success. Across all countries, academic skills were the least mentioned factor of success, relative to the three other categories. Aside from this similarity, countries did differ in terms of the categories that were most emphasized.

In South Africa, the emphasis was on workforce and society characteristics, such as job readiness skil morals and values, ability to provide basic needs, and positive contribution to society, followed by character traits-aspects that are closely tied to individual learners' success beyond school. In Kenya, the emphasis was also on workforce and society characteristics, but this was followed by 21 st century skills, nominated primarily by government personnel. In Mexico, overPll, equat weight was given to 21st century skils a che chariners, and nongovernment and government personnel placing
more emphasis on 21st century skills and parents and teachers placing more emphasis on character traits. Here, the idea of the stakeholders closest to the child focusing on the individual child's success and the stakeholders more removed from the child considering the larger societal priorities comes up again, with hers as the connectic Finally in the Philppines, character trats were mos. noted, followed closely by workforce and society characteristics, and 21st century skills. Notably, academic skills were not mentioned by any stakeholder groups in the Philippines or Mexico.

"Valued Skills"

There were strong differences across countries between what were seen as success characteristics and valued skills. Academics was no longer the leas emphasized category and was, in fact, one of two most emphasized categories, at least in the Philippines. Parents and teachers in all countries seemed to value academic skills. But beyond academic skills, the categoies that were most enphasized by colls, 
Similarities and differences were evident when comparing countries on factors that characterize success and the skills that are of high value for a particular country. What was emphasized for success was not necessarily emphasized for skills. Collectively, countries perceived workforce and society characteristics and character traits as critical contributors to learner success. On the other hand, countries unanimously identified 21 st century skills over the three other categories as the most important skills for learners. This is in line with current global dialogue and the growing recognition at the country level concerning the importance of 21st century skills.

success. Across all four countries, 21 st century skills were the most identified category and were more emphasized in Mexico than in the other countries. In South Africa, the 21st century skills mentioned by the most stakeholders were communication and listening. In Kenya, social skills, including collaboration and communication, as well as critical thinking, were identified by the most stakeholders, with the Philippines also nominating social skills such as communication Mexico stakeholders primarily nominated skills related to the self, including self-awareness and self-regulation, as well as other generic skills, such as creativity and decisionmaking. These differences should not be interpreted comparatively. Respondents in each country were not each given a set list of skills to respond to. Rather, each set of respondents volunteered the skills.
At the same time, identification of character traits, specifically in Kenya and the Philippines, was less prevalent, although character traits still held high value in Mexico and South Africa. In Kenya, workforce and society characteristics continued to be emphazized, simlar to identication of the characteristics (izs 21 st century skills and academic skills were the mos emphasized categories, followed by workforce and society characteristics.

To summarize, similarities and differences were evident when comparing countries on factors that characterize succe ( sized, similar to identification of the characteristics characterize success and he skills that are of high
Collectively, countries perceived workforce and society characteristics and character traits as critical contributors to learner success. On the other hand, countries unanimously identified 21 st century skills over the three other categories as the most important skills for learners. This is in line with current global dialogue (United Nations, 2016), as well as the growing recognition at the country level (Care, Anderson, and Kim, 2016. Kim Care, and Ditmore, 2017) concerning the importance of 21st-century skills.

\section{Limitations}

There were differences in endorsement patterns of skills and characteristics among countries and stakecoss countries. It is differences are attributable to the survey process. Although each survey used the same procedures and prompts, the qualitative nature of interviews and focus groups lends itself to possible bias due to country-level questioning and facilitation techniques. In addition, despite strategies used by interviewers to clarify the nature of terms and language language differences contribute to different understandings of terms. Another source of variance is the composition of the focus groups themselves and the selection of individual representatives of stakeholder groups for interviews. More information about the composition of the stakeholder groups are described in the country reports in the previous section.

Attitudes and Perceptions Reflect Country Priorities

While countries may differ on the factors that characterize success and the skills and characteristics that are highly valued, a common aspect underlying country perspectives centers on the fact that attitudes and perceptions of key education stakeholders are

influenced by the current priorities of each country.
All four countries are striving to equip their citizens with the knowledge, values, skills, and competencies that will allow them to contribute positively to society as a whole and thrive in a changing and challenging world. In addition, all four countries value and endorse access to quality education for all as a means of enhancing the skills necessary to contribute to the century skis we mentoned most frequently in all countries and by all of the stakeholder groups as having high value provides some indication that there is countrywide recognition of aspirations to broaden the educational provision beyond academic skills, which has traditionally been the focus.

At the same time, countries place special emphasis on certain skills, competencies, traits, and values that are distinct to each country, which may be a function of the country's unique historical and societal context, as well as its national priorities.

In South Africa, workforce and society characteristics and character traits are prominent factors of success. The country as a whole has a high rate of unemployment, which is even larger for those ages 15-24. As such, making sure students are prepared for the workforce is of great importance. Given that education level is a major contributing factor of employment, a frequently mentioned concern was that schools are not adequately preparing students for what is in demand by the labor markets. Furthermore, stakeholders in South Africa often brought up desires for inclusion, equity and diversity miroring the goals of their edequity, and divensy mirroing the goals of their education system of addressing apartheid's legacy of inequity. The notion that the country's success in meeting the goals is not achievable by an individual, but by collective effort that requires citizens to give back to the community and help others succeed, resonated with all stakeholders.

Stakeholders in Kenya also emphasized workforce and society characteristics as factors that character- 
ize success, although government personnel strongly identified 21st century skills to describe success. Promoting sustainable development and ensuring that learners' maximum potential is met are key goals of the country. In addition, there is recognition that future labor markets will require non-routine tasks and problem solving abilities. The focus on workforce and society characteristics by most stakeholder group inforces the importance of improving education quality to align with the country's economic priorities. Although academic skills were mentioned as somewhat important, stakeholders, especially parents and teachers, specifically brought up the importance of talent development, extracurricular activities, and personal development. This is unique to Kenya and may be a counter to the exam-oriented neture of the may be a count to the exam-oriented nature of the potential of all children, even those who are not "academically inclined," so focusing on nonacademic activities, such as sports, is seen as another pathway to success. Furthermore, the identification of 21st century skills by government personnel is expected given the new curriculum reform effort that is intended to equip citizens with those skills so that they can contribute to society.

In Mexico, there is evidence that priorities have shifted from providing access to education to ensuring quality education for all by 2030; this is reflected in the attitudes and perceptions of the stakeholders. Twenty-first-century skills were frequently mentioned, more than in the three other countries, in terms of bo success and highly valued skills. The perspectives of key education stakeholders reflected the seven domains of learning that are highlighted in the new 2016 curriculum, including critical and reflective thinking. interpersonal skills, and emotional development.

In the Philippines, education is highly regarded as are teachers, notwithstanding that salaries and working conditions are not good. Philippine parents are firmly focused on the value of academic skills, mirrored to some extent by teachers, although what parents value in a successful individual is self-sufficiency as well as responsibility - which is associated with looking after family. Accordingly, work-related skills were identified as well as the capacity to deal with everyday domestic life. Concepts of a broader range of skills as contributing to development of the individual remain primarily in the sights of higher-level government stakeholders. With the Philippines' major $\mathrm{K}$ to 12 education reform and its focus on the need for students to understand what they learn and to apply it, the nomination of $21 \mathrm{st}$ century skills by teachers and higher-level government stakeholders is consistent with concerns of their Department of Education

\section{ISSUES}

\section{Tradition versus breadth}

Across the four countries, it is clear that there is perceived tension across some stakeholder groups between education focused on holistic developmen and education providing access to traditionally valued academic outcomes. Education systems in the focus countries reflect classrooms where assessment is used to rank students, and those students most highly ranked are destined for progression through the system. This is indicative of systems in which there is room for relatively few at the highest levels of education, and normal distribution assumptions underlie both assessment and the perception that a chosen

ew will reach the top of the pyran is counter to a breadth of skills approach, $w$ for all child a breach of skls approach, which seeks cation, as described by the Sustainable Developmen Goals.

Parents who believe that academic excellence is the pathway to societal success or wealth may be uneasy about shifts in educational aspiration toward new sets about shifsi here traditional skill achievement has been marker for future success, parents are placed in a difficult situation if asked to value other skills. For example, if in the Philippines English proficiency has been a skill highly regarded in the past, parents now may feel uneasy with a focus on the mother tongue.

Teachers also may be uneasy about the introduction of new areas of expertise in which they might not feel confident. Already many teachers are uncomfortable about their lack of ICT expertise and cite their students' greater proficiency in this area. For teachers who have themselves learned in a system where knowledge is highly valued and teachers have bee the main source of knowledge for their students, moving to a system in which this role is less valued can be threatening.

For education policymakers, it is plausible that many do not have the classroom experience or expertise to understand the implications of this skills shift. This goes to the primary issue in implementation of bread of skills: lack of knowledge. This reality was very clearly expressed in a regional study undertaken by the Network on Education Quality Monitoring in the Asia-Pacific (NEQMAP) (Care and Luo, 2016) where both education leadership personnel and teachers identified lack of training in "skills" as a primary blocker to implementing an integrated breadth of skills educational approach in the classroom. Although both education leaders and teachers throughout the Asia-Pacific identified that training is made available, this is seen as insufficient in terms of the detail and for associated assessment activities.

\section{Broad versus narrow}

Audits of early childhood education websites generate lists of expectations of what is to be provided to children and what they should experience-for example, that they should be exposed to opportunities for creativity, for exploration, and for interaction with their environment and with one another. In contrast, audits of basic education sites generate lists of basic skillsfor example, that children should become literate and numerate- and then detail about the levels through which students should proceed with these skills, in addition to early scientific understanding, and basic history and geography. The text changes from experiencing and exploring to learning and reaching specific outcomes. By early secondary education, the specificity has increased, and more sophisticated literacy, numeracy, and scientific outcomes are described. At exit from the secondary school system, websites identify graduates as those who can apply their thinking to big issues, who have the skills to cope with the world of work, and who are sufficiently literate and numerate to "make a difference." So, the goals move from broad in early childhood, to more narrow in primary and early secondary, and through to readiness for the waiting world by the end of formal education.

\section{Resource need: Skills knowledge}

Although the need for funding is consistent across any major changes, the other major resource call is upon expertise. The four countries each have their particular challenges in terms of teaching force, but the demands of the skills shift are beyond the underlying teacher quality, accreditation, and expertise issues. The skills issue confronting these countries is not very different from that confronting countries which are regarded as achieving higher outcomes in education stakes. For example, based on the mapping data (Care et a 2016: Kim et 21. 2017), although countries such as the Republic of Korea, Finland, and New tries such as the Republic of Koea, Finland, and New Zealand have similarly identified breadth of skills as an essential component in their educational aspirations, they are yet to finalize well-defined learning progressions of the skills of interest.

Nominations of valued skills by government personnel reflect generally what has been depicted in the mapping visualization A broad range of skills is acmapping visua 
Understanding that children need a particular set of skills to live constructively in the 21 st century is not the same as understanding in depth what those skills are, how they develop, or how to teach them.

working most closely with the child, also acknowledge the importance of skills for success in school and beyond. However, nominations about factors and skills related to success from the groups in the middle, such as teacher trainers and education administration personnel, are sparse. These groups are those that have a say in how the implementation happens, how teachars ar how the implemention happens, how teachThese are precisely the areas in which knowlec knowledge and expertise about breadth of skills is lacking.

\section{Key findings}

1. Across all countries, 21 st century skills are more frequently identified as of value relative to the categories of academic skills, character traits, and workforce and society characteristics. This pattern is different from success, in which most countries emphasize character traits and workforce and society characteristics.

2. For key education stakeholders within each country, there is a tension between the desire that learners should be holistically developed and have a broad range of skills, and the current structures in the education system, such as the exam-oriented nature of the curriculum and pressure to cover congested curricula, that limit what is taught in classrooms.

3. Attitudes and perceptions of key stakeholders reflect the priorities of each individual country. All countries face similar challenges; however, there are challenges that are unique to a particular coun- try depending on the context and priorities. In other words, the individual context and priorities of the country permeate the educational dialogue.

4. There appears to be less dialogue about educathe parent and teacher groups, and the government personnel (i.e., teachers of teachers and representatives of NGOs). In part, among these groups, this is supplanted by a focus on what skills or characteristics are needed by teachers, rather than children. Whether the sparseness is real or a function of the data collection method is not clear.

\section{The next challenge}

The defining characteristic of a 21st century skill is that an individual or group of individuals can bring that competency to bear in and across new situationsincluding those associated with or within technology environments.

Understanding that children need a particular set of skills to live constructively in the 21st century is not the same as understanding in depth what those skills are, how they develop, or how to teach them. For instance, there are thousands of research articles and texts on how literacy and numeracy develop and on how to teach and assess th as 21 st century skills. This reality is one major challenge for countries in the implementation phase of breadth of tional issues or importance of different approaches to education in stakeholder groups that fall between skills. Global initiatives designed to explore how to leach and assess 21 st century skills (e.g. Griffin and Care, 2015) have provided early proof of examples, but by and large such examples have not been sufficiently practical or technology-free to inform country development of skills integration in pedagogy, curriculum, and assessment. Although many challenges confront countries today in this education shift, this issue of skills knowledge is a critical one.

It is time to acknowledge the movement of education systems toward skills and to build the regional and

global evidence of the "whats" and "hows" of the "world of skills." A huge amount of work needs to be done, and there is a great deal that countries, their ed ucators, and researchers can learn from one another. Coordinated and collaborative research across countries provide both economies of effort and the benefits of learning from one another, as exemplified by the work of UNESCO Bangko work $\mathrm{UN}$ Instiutes Network in the Asia Pacilic on policy and teaching of transversal competencies (e.g., UNESCO, 2015) as well as NEQMAP on assessment of transve sal competencies (e.g., Care and Luo, 2016).

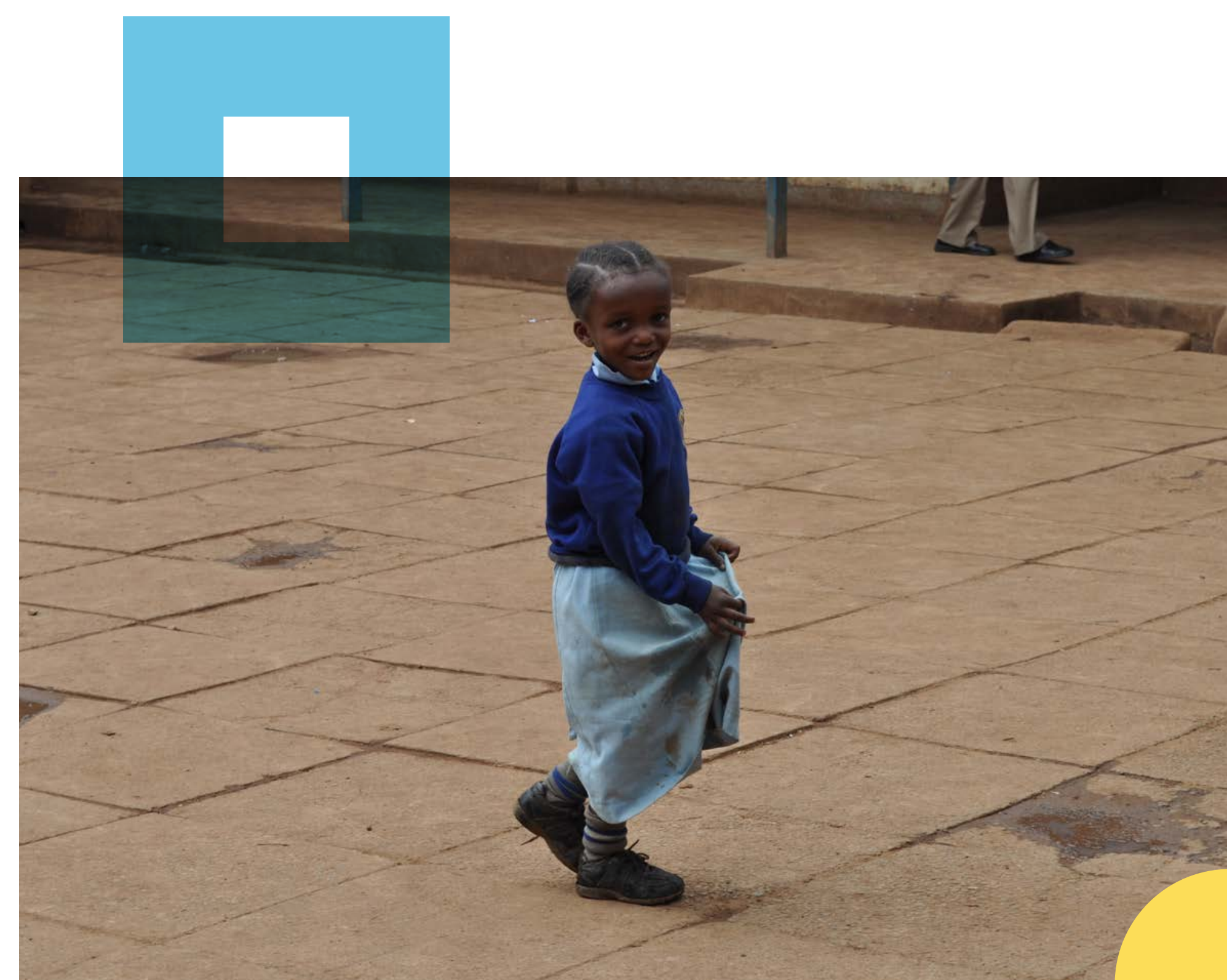




\section{ENDNOTES}

1 http://atlasti.com/

2 http:///www.qsiniternational.com/produc

3 The term colored is used in South Africa, including on the national census, for persons of mixed race ancestry

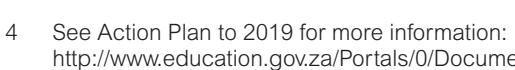

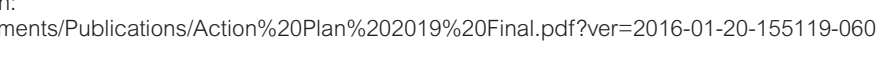

5 Meaning eight years of primary school, four years of secondary, and four years of tertiary. Previously the government followed the Britith system: seven years of prima-

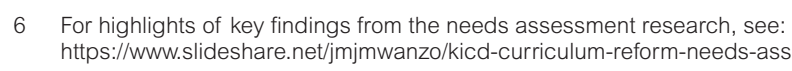

7 The provision of Grades 11 and 12 does not imply that enrollment is mandatory

8 hitps://mww.actrc.org

\section{REFERENCES}

Ananiadou, K., and M. Claro. 2009. "21st Century Skills and Competencies for New Millennium Learners in OECD Countries." OECD Education Working Paper 41, OECD
Publishing.

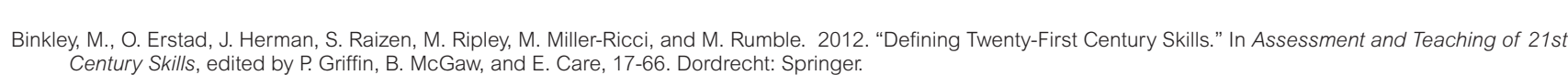
Brewer, L. 2013. Enhancing the Employability of Disadvantaged Youth: What? Why? and How? Guide to Core Work Skills. International Labour Organization. Care, E., and R. Luo. 2016. Assessment of Transversal Competencies: Policy and Practice in the Asia-Pacific Region. UNESCO.

Care, E., and K. Anderson. 2016. How Education Systems Apprrach Breadth of Skills. Center for Universal Education at the Brookings Institution, Washington, D.C. Care, E., K. Anderson, and H. Kim. 2016. Visualizing the Breadth of Skills Movement across Education Systems. Center for Universal Education at the Brookings Institution.

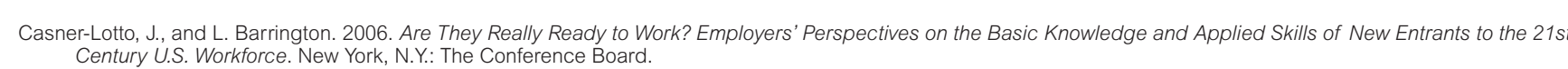
Creswell, J. W. 2014. Research Design: Qualitative, Quantititive, and Mixed Methods Approaches. 4th ed. Thousand Oaks, Calif: Sage,

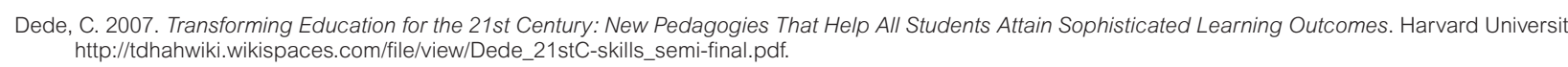
Delors, J. 1996. Learning: The Treasure Within. Report to UNESCO of the International Commission on Education for the Twenty-first Century. Paris: UNESCOC Denham, S. A. H. H.H. Bassett, and K. Zinsser. 2012. "Early Childhood Teachers as Socializers of Young Children's Emotional Competetence." Early Childhood Education
Journal $40,137-133$.

Griffin, P., and E. Care, eds. 2015. Assessment and Teaching of 21st Centurry Skills: Methods and Approach. Dordrecht: Sppinger. Kalantizis, M. and B Cope 2008 New Learning. Elements of Science of Education Cambridge, UK. Cambridge Unversity Pros

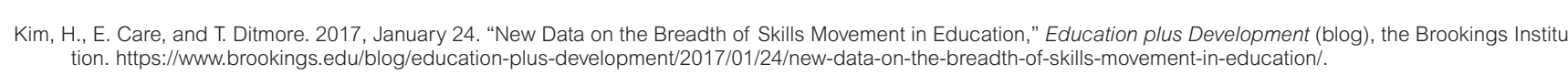

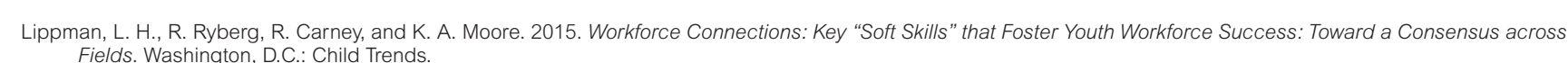
Morgan, D. 1996. "Focus Groups." Annual Review of Sociology, 22(1), 129-152.

Peek, L., and A. Fothergill. 2009. "Using Focus Groups: Lessons from Studying Daycare Centers, 9/11, and Hurricane Katrina." Quallitative Research, 9(1), 31-59. Pellegrino J. W. and M. Hilton. 2012. Education for Life and Work: Developing Transferable Knowledge and Skills in the 21st Century. Washington, D.C.: National Research
COuncil Reimers, F. M. and C.K. Chung, eds. 2016. Teaching and Learning for the Twenty-First Century: Educational Goals, Policies and Curricula from Six Nations. Cambridge
Mass. Havvard dducation Press Rotherham, A. J., and D. T. Willingham. 2010. “ "21st-Century' Skills: Not New, but a Worthy Challenge." American Educator, 17-20, Spring. Trilling, B., and C. Fadel. 2009. 21 st Century Skills: Learning for Lifie in Our Times. San Francisco: Jossey-Bas.

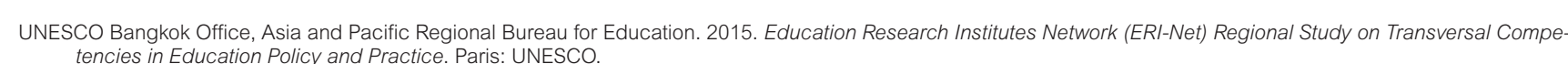

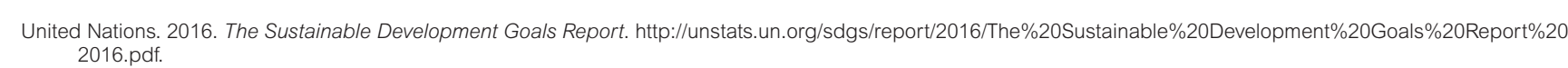
Wiggins, G., and McTighe, J. 2005. Understanding by Design Exxanded Second Edition). Alexandria, Va: ASCD. 


\section{Mexico}

Abadzz, H. 2016. Iraining 21st-century workers: Facts fiction and memory llusions International Review of Education. 62: 253. doi:10.1007/s11159-016-9565-6

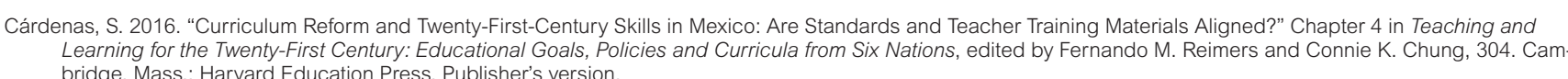

CIA World Factbook. 2017. "North America: Mexico." https://Mww.cia.gov/library//publications/the-world-factbook'geos/mx.htm.

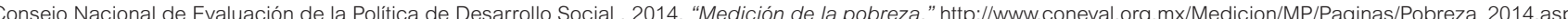
Esquivel, G. 2015. Extreme Inequality in Mexico: Concentration of Economic and Political Power. Mexico: Mexico City. Oxiam Mexica

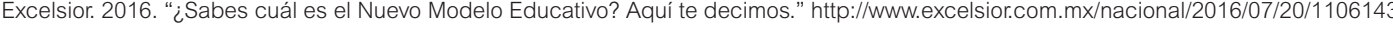

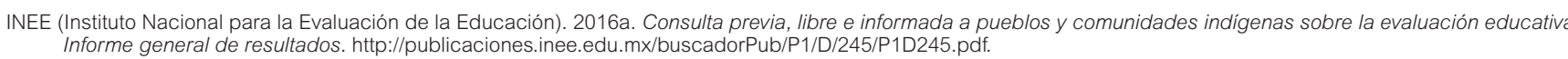

INEE. 2016b. Panorama Educativo de México 2015. Indicadores del Sistema Educativo Nacional. Educación Básica y Media Superior. Mexico: Mexico City. http:///publica-

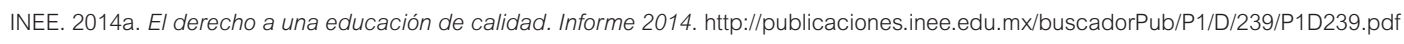

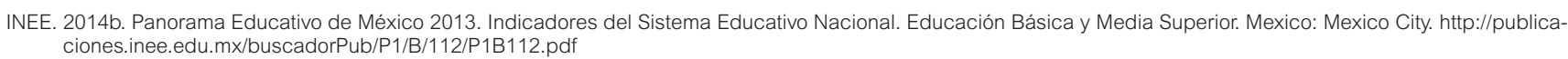

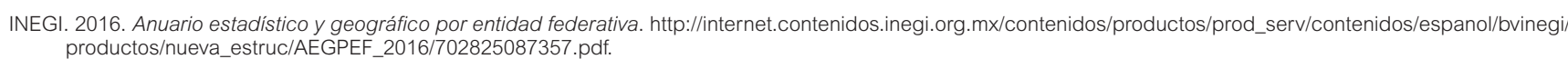

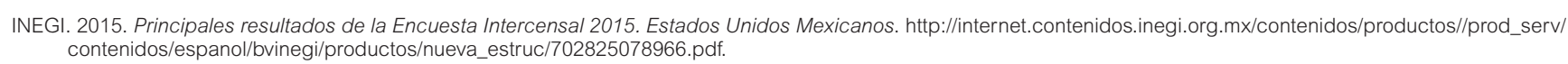
OECD. 2016a. Country Note: Mexico. Results from PISA 2015. Paris: OECD Publishing. htpp://mww.oecd.org/mexico/PISA-2015-Mexico.pdf.

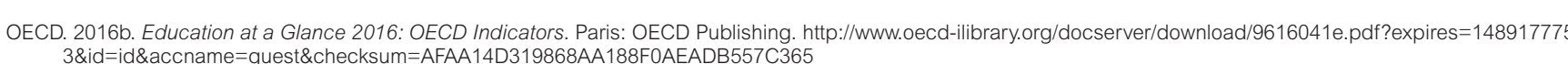
OECD. 2013. Education Policy Outtook: Mexico. OECD Publishing, Paris. http://Www.oecd. org/edu/EDUCATION\%20POLICY\%20OUTLOOK\%20MEXICO_EN.pdf. OECD. 2010. Improving Schools: Strategies for Action in Mexico. Paris: OECD Publishing

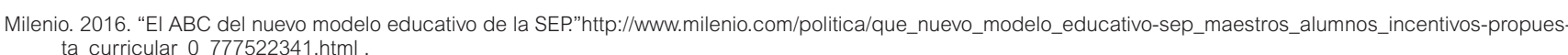

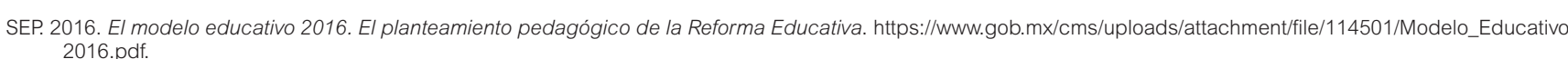

SEP. January 2013. Visión y misión de la SEP. https://www.gob.mx/sep/acciones-y-programas/vision-y-mision-de-la-sep? ?idiom=es

The World Bank. n.d. "Mexico Data." http://data.worldbank.org/country/mexico.

Zorrilla, M. 2008. La escuela secundaria mexicana. Un estudio multinivel de los effectos escolares y sus propieddades cientfficas. Ph.D. thesis. Universidad Anáhuac, Mexico.

\section{South Africa}

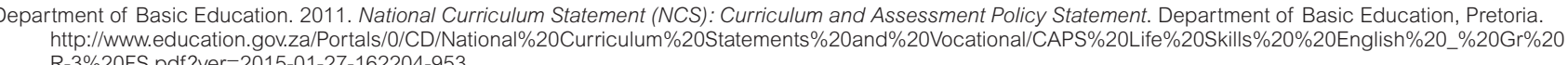

Department of Basic Education. 2014. Report on the Annual National Assessment of 2014. Department of Education, Pretoria

Department of Basic Education. 2015. Action Plan to 2019: Towards the Realisation of Schooling 2030. Department of Education, Pretoria

Department of Basic Education. 2016a. "About Basic Education." http///www.education.goviza/Aboutus/AboutDBE.aspx.

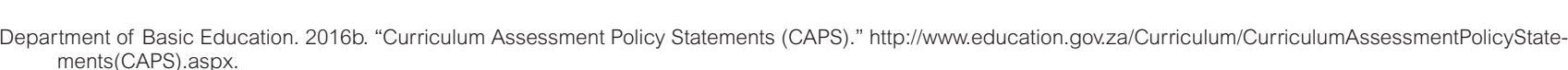
Department of Basic Education. 2017a. "About Basic Education." Retrieved from http://Mmw.education.goviza/AboutUs/AboutDBE.aspx.

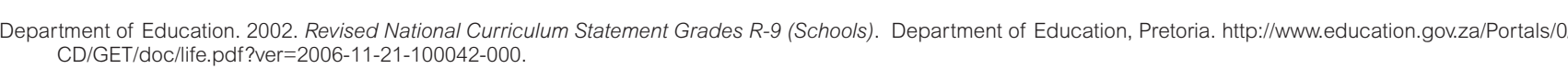

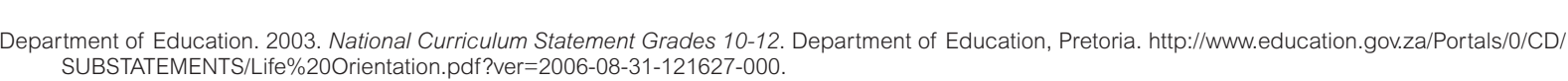
Department of Education and UNICEF. 2008. Implementation Guidelines: Safe and Caring Child-Friendly Schools in South Africa. Department of Education, Pretoria. Hall, K. 2015. "Children's Access to Education." In South African Chidd Gauge, edited by A. De Lannoy, S. Swartz, L. Lake, and C. Smith. Cape Town: University of Cape Town. Hall, K., and W. Sambu. 2015 . "“ncome Poverty Unemployment and Social Grants." In South African Child Gauge, edited by A. De Lannoy, S. Swartz, L. Lake, and C. Smith.
Cape Town: University of Cape Town.

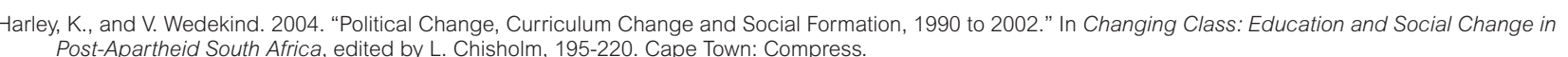
Jansen, J., and N. Taylor. 2003. Educational Change in South Africa 1994-2003: Case Studies in Large-Scale Education Reform. The World Bank

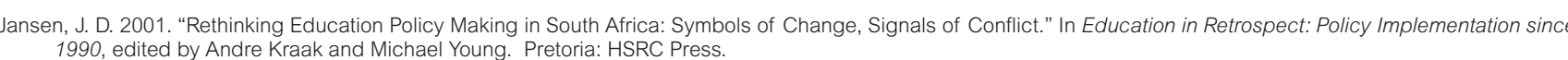
Maluleka, S. 2011. "Curriculum: Back to the Blackboard." Daily News, August 10. http://mww.iol.co.za/dailynews/sport/curriculum-back-to-th-blackboard-1115196

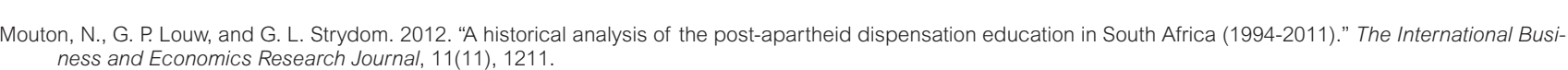

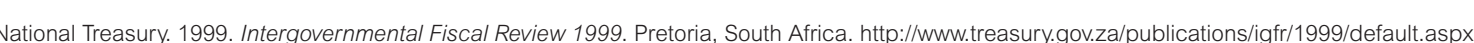

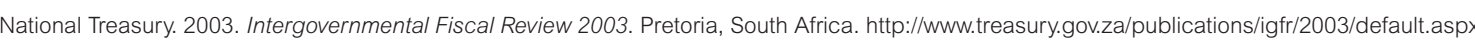

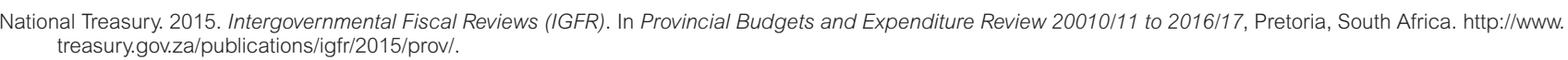
Organisation for Economic Co-operation and Development. 2008. Reviews of National Policies for Education: South Africa. OECD Publishing. Spaull N. 2013. South Africa's Education Crisis: The Quality of Education in South Africa 1994-2011. Report commissioned by Centre for Develooment \& Enterprise Statistics South Africa. 2016c. Mid-year Population Estimates, Statistical Release P0302. Statistics South Africa, Pretoria Statistics South Africa. 2016a. Community Survey 2016, Statisticial Release P0301. Statistics South Africa, Pretoria

Staisticics South Africa. 2016. GHS S Series Report Volume VIII: Water and Sanitation, in-Depth Analysis of the General Household Survey $2002-2015$ and Community Survey Statistics South Africa. 2016d. Quarterly Labour Force Survey: Quarter 4. 2016, Statistical Release P0211. Statistics South Africa, Pretoria Steyn. H. J. S. C. Steyn. E. A. S. De Waal, C. C. Wolhuter 2011. The South African Education System. Keurkopie: Potchefistroom. 


\section{Kenya}

Akala, W. J. 2002. "World BankIMIMF Policies on Teacher Recruitment and Re-Sizing in Kenya: A Critique." Paper presented at Southeastern Regional Seminar in African Stud-
IeS (SERSAS). Champaign, III: SERSAS. Eisemon, T. . . 1990. "Examinations Policies to Strengthen Primary Schooling in African Countries." International Journal of Educational Development, 10(1), 69-82 Eshivani, G. S. 1990. Implementing Educational Policies in Kenya. World Bank Discussion Papers No. 85. Africa Technical Department Series. Washington, D.C.: The World Hornsby, C. 2012. Kenya: A History Since Independence. New York, N.Y. IB Tauris.

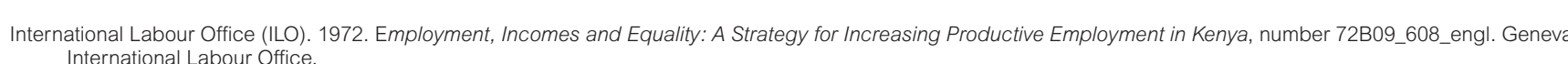
Kenya National Bureau of Statistics. 2014. Kenya Facts and Figures, 2014. Kenya National Bureau of Statistics

Kenya, Republic of. 1965. African Socialism and Its Application to Planning in Kenya

Mackatiani, C. M. M. Imbovah, N. Imbova, and D. K. Gakunga. 2016. "Development of Education in Kenya: Influence of the Political Factor beyond 2015 MDGs." Journal of
Education and Practice, 7(11),55-60.

MoEST. 2012. Reforming Education and Training Sectors in Kenya. Republic of Kenya.

MoEST. 2015. National Curriculum Policy. Republic of Kenya

NCEOP. 1976. Report of the National Committee on Educational Objectives and Policies.

Nicolai, S. A. A. Prizzon, and S. Hine. 2014. Beyond Basic: The Growth of Post-Primary Education in Kenya. Overseas Development Institute (ODI) Development Progress
Report. London: Overseas Development nstitute.

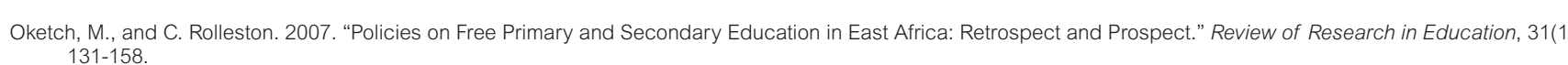

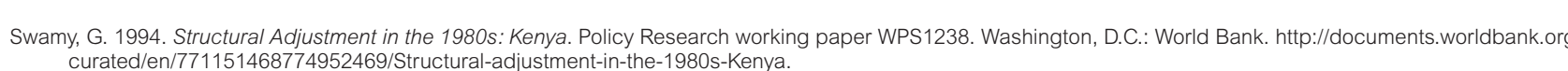

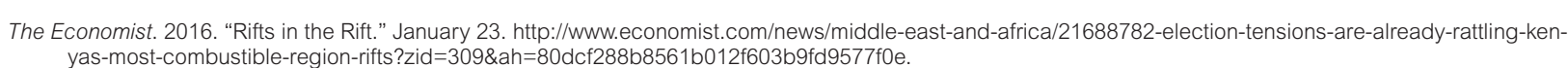

The World Bank. 2017, "Kenya: Population, Total" (data file). htip:///data. worldbank.org/country/kenya.

UNESCO International Bureau of Education (IBE). 2010-11. "Kenya." World Data on Education, 7th Edition.

United Nations Statisitics Division. 2017. "Kenya." U.N. data

Wamahiu, S. 2015. Value-Based Education in Kenya: An Exploration of Meanings and Practices. Synthesis Report. Women Educational Researchers of Kenya and MoEST

Watkins, K., and Woubedle Alemayehu. 2012 . Financing for a Fairer, More Prosperous KKnya: A Review of the Public Spending Challenges and Options for Selected Arid
and Semi-Arid Counties. Center for Universal Education, The Brookings Institution.

\section{Philippines}

Abinales, P., and D. J. Amorososo. 2005. State and Society in the Philipoines. New York: Roman and Littefieled Publishers inc.

Bauzon, L. E. 1981. Deficit Government: Mexico and the Philipoine Situado, 1600-1804. Tokyo: The Centre for East Asian Cultural Studies Official Gazette. 2016. "The Philippines." htip://Mwrw.gou.ph/aboutphililppines/

Gloria Macapagal-Arroyo Initiatives. n.d. http://Mww.macapagal.com/gma/initiatives/edureform.php.

National Economic Development Authority 2014. Socioeconomic Report 2014. Pasig. National Economic Development Autholy

Philippine Statistics Authority. 2016a, May. Labor Force Survey. Philippine Statistics Authority

Philippine Statistical Authority. 2016b, October. https://psa.gov.ph/poverty-press-releases. 
